\title{
Retrieval of Atmospheric Parameters and Surface Reflectance from Visible and Shortwave Infrared Imaging Spectroscopy Data
}

\author{
David R. Thompson ${ }^{1}$ (D) Luis Guanter ${ }^{2}$ - Alexander Berk ${ }^{3}$ - Bo-Cai Gao ${ }^{4}$. \\ Rudolf Richter $^{5}$ - Daniel Schläpfer ${ }^{6}$. Kurtis J. Thome ${ }^{7}$
}

Received: 5 October 2017 / Accepted: 7 July 2018

(c) Springer Nature B.V. 2018

\begin{abstract}
Remote imaging spectroscopy in the $0.4-2.5-\mu \mathrm{m}$ visible and shortwave infrared (VSWIR) range captures the majority of solar-reflected energy and enables a wide range of earth surface studies. This spectral range is also influenced by atmospheric effects including absorption from atmospheric gases and aerosols, Rayleigh scattering, and particle scattering. Globally consistent surface measurements must compensate for these atmospheric effects. This article reviews the physical and mathematical foundations of modern VSWIR atmospheric retrieval, focusing on imaging spectrometers. We assess sensitivity of the retrieval to errors in atmospheric state estimation. Finally, we describe some promising avenues of future research to support the next generation of orbital imaging spectrometers.
\end{abstract}

Keywords Imaging spectroscopy · Atmospheric correction · Hyperspectral imaging · Surface reflectance

\section{Introduction and Background}

The 0.4-2.5- $\mu \mathrm{m}$ visible shortwave infrared (VSWIR) range captures the majority of solar-reflected energy, enabling diverse spectroscopic studies of the Earth's surface. Applications span aquatic and terrestrial ecology (Mumby et al. 2004; Ustin et al. 2004),

David R. Thompson

David.R.Thompson@jpl.nasa.gov

1 Jet Propulsion Laboratory, California Institute of Technology, 4800 Oak Grove Dr., Pasadena, CA 91109, USA

2 GFZ German Research Centre for Geosciences, Helmholtz Centre Potsdam, Telegrafenberg, Building A 17, Room 20.22, 14473 Potsdam, Germany

3 Spectral Sciences, Inc., 4 Fourth Ave., Burlington, MA 01803, USA

4 Naval Research Laboratory, 4555 Overlook Ave., Washington, DC 20375, USA

5 German Aerospace Center (DLR), Münchener Straße 20, 82234 Weßling, Germany

6 ReSe Applications LLC, Langeggweg 3, 9500 Wil, Switzerland

7 NASA/Goddard Space Flight Center, 8800 Greenbelt Rd, Greenbelt, MD 20771, USA 
urban and agricultural studies (Herold et al. 2004), geology, hydrology, natural hazards remediation (Clark et al. 2003), and many more. Such investigations must estimate spectral reflectance-roughly speaking, the fraction of incident light that is reflected from the land or water surface (Schaepman-Strub et al. 2006). This involves first calibrating the measurement from raw instrument digital numbers (DN) to spectral radiance, and then inverting atmospheric influence to estimate surface properties (Fig. 1).

This article considers atmospheric inversion for orbital VSWIR imaging spectrometers. Future orbital missions will enable global studies comparing different regions and continents to understand the Earth system. Such studies have challenges commensurate with their value: estimating surface reflectance without biases across varied surface and imaging conditions requires consistent, accurate atmospheric correction. Moreover, global studies will lack in situ validation data for most scenes, so it will be important to understand any uncertainties that influence downstream analysis. We will investigate the challenge from first principles, surveying algorithms used in contemporary atmospheric correction practice. We aim to determine: first, the most significant uncertainties in global-scale atmospheric correction, and their effect on the resulting reflectance; and second, the best opportunities for future research to improve atmospheric correction accuracy in support of global missions.

The most important uncertainties depend on the specific instrument and application. Here, we address them in a general sense with an idealized instrument similar to many existing and planned VSWIR spectrometers: a spectral range of 0.4-2.5 $\mu \mathrm{m}$ sampled at $0.01-\mu \mathrm{m}$ intervals, a ground sampling distance (GSD) of $30 \mathrm{~m}$, and noise equivalent change in radiance $(\mathrm{NEdL})$ on the order of $0.01 \mu \mathrm{W} \mathrm{cm} \mathrm{sr}^{-1} \mathrm{~nm}^{-1}$. This is sufficient to reveal general sensitivity trends, and the analytical framework is generic if precise predictions for a specific instrument are needed.

We begin by reviewing the radiative transfer background and atmospheric processes relevant to mapping spectrometers in the VSWIR range. We describe retrieval algorithms including estimation of aerosol and gas interference as well as correction for surface effects such as bidirectional reflectance and topography. Finally, we describe common uncertainties in calibration and atmosphere and simulate propagation of errors using a state-of-theart atmospheric radiative transfer code. This permits a sensitivity analysis tracing imperfect atmospheric retrievals to errors in downstream analyses. We close by summarizing our findings and outlining future research that could address remaining challenges.
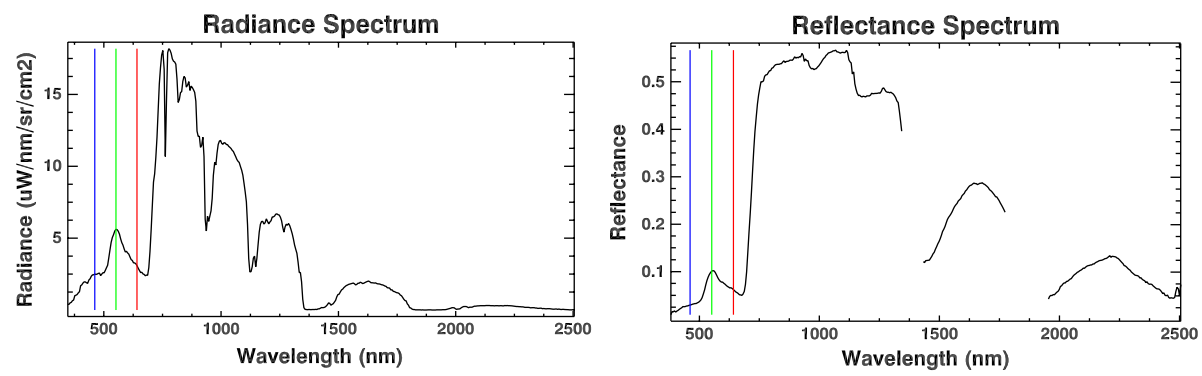

Fig. 1 Typical analysis progresses from radiance at the sensor (left) to atmospherically corrected reflectance (right). The plot shows individual spectra acquired by NASA's Next Generation Airborne Visible Infrared Imaging Spectrometer (AVIRIS-NG) instrument. Adapted from Thompson et al. (2018a). Red, green, and blue lines indicate visible wavelengths 


\section{Principles of Radiative Transfer for VSWIR Imaging Spectroscopy}

Global atmospheric correction begins with the physics of radiative transfer. This is not always necessary in airborne investigations, where physically motivated atmospheric correction is just one of several options (Gao et al. 2009). Alternatives include empirical approaches like scene averaging (Kruse 1988), flat fielding (Roberts et al. 1986), quick atmospheric correction (QUAC, Bernstein et al. 2005), and cloud shadow methods (Reinersman et al. 1998). Empirical methods are useful in isolated cases, but rely on specific characteristics of the scene-such as the presence of clouds, a spatially homogeneous atmosphere, or a known distribution of spectra-which precludes scaling them to global missions. Empirical line methods (Conel 1987; Thompson et al. 2016a) fit scene-specific corrections to match in situ reference spectra obtained by field teams. These relationships can be highly accurate over small geographic regions but also fail on a global scale. We focus here on physically motivated corrections based on radiative transfer models, which have superior stability and analytical interpretability for cross-regional studies.

Physically based methods for the retrieval of atmospheric parameters and surface reflectance rely on mathematical models of the spectral radiance reflected by the Earth's surface and atmosphere at the top of atmosphere (TOA). They typically decompose this measurement into a sum of radiative contributions from different processes, such as the photons scattered by the atmosphere into the sensor line of sight or those multiply scattered between the atmosphere and the surface. Tanré et al. (1981) proposed one useful and accurate formulation of the TOA radiance, implemented in the second simulation of the satellite signal in the solar spectrum (6S) code (Vermote et al. 1997b). It is part of the operative Moderate Resolution Imaging Spectroradiometer (MODIS) atmospheric correction algorithm (Vermote et al. 1997a) and the ATmospheric REMoval (ATREM) atmospheric correction code for VSWIR imaging spectrometers (Gao et al. 1993). In this formulation, the intrinsic directional properties of surface reflectance are rigorously coupled with the downwelling direct and diffuse irradiance fluxes, whereas gas absorption is decoupled from the total transmittance for practical reasons and included in the formalism as a multiplicative factor. The upward TOA radiance is expressed as a sum of five terms: (1) the photons reflected by the atmosphere before reaching the surface; (2) the photons directly transmitted from the Sun to the target and directly reflected back to the sensor; (3) the photons scattered by the atmosphere, then reflected by the target and directly transmitted to the sensor; (4) the photons directly transmitted to the target but scattered by the atmosphere on their way to the sensor, and (5) the photons having at least two interactions with the atmosphere and one with the target surface. The observed spectral reflectance at the TOA $\left(\rho_{\mathrm{obs}}^{*}\right)$, resulting from the normalization of the TOA radiance $L_{\mathrm{obs}}$ by the incoming extraterrestrial solar irradiance $\mu_{0} F_{0}$, can be written:

$$
\begin{aligned}
\rho_{\text {toa }}^{*}\left(\mu_{0}, \mu_{\mathrm{v}}, \phi\right)=\frac{\pi L_{\mathrm{obs}}}{\mu_{0} F_{0}}= & T_{\mathrm{g}}\left(\mu_{0}, \mu_{\mathrm{v}}\right)\left[\rho_{\mathrm{c}}\left(\mu_{0}, \mu_{\mathrm{v}}, \phi\right)\right. \\
& +e^{\frac{-\tau}{\mu_{0}}} e^{\frac{-\tau}{\mu_{\mathrm{v}}}} \rho_{\mathrm{s}}\left(\mu_{0}, \mu_{\mathrm{v}}, \phi\right) \\
& +e^{\frac{-\tau}{\mu_{\mathrm{v}}}} t_{\mathrm{d}}\left(\mu_{0}\right) \rho_{\mathrm{hd}}+e^{\frac{-\tau}{\mu_{0}}} t_{\mathrm{d}}\left(\mu_{\mathrm{v}}\right) \rho_{\mathrm{dh}} \\
& +t_{\mathrm{d}}\left(\mu_{0}\right) t_{\mathrm{d}}\left(\mu_{\mathrm{v}}\right) \rho_{\mathrm{hh}} \\
& \left.+\frac{\left.e^{\frac{-\tau}{\mu_{0}}}+t_{\mathrm{d}}\left(\mu_{0}\right)\right]\left[e^{\frac{-\tau}{\mu_{\mathrm{v}}}}+t_{\mathrm{d}}\left(\mu_{\mathrm{v}}\right)\right] S_{\mathrm{c}}\left(\rho_{\mathrm{hh}}\right)^{2}}{1-S_{\mathrm{c}} \rho_{\mathrm{hh}}}\right]
\end{aligned}
$$


Here $\mu_{0}$ is the cosine of the solar zenith angle, $\mu_{\mathrm{v}}$ is the cosine of the view zenith angle, $\varphi$ is the relative azimuth angle between the illumination and the observation, and $T_{\mathrm{g}}$ is the transmittance due to gas absorption. There are also several terms related to the influence of atmospheric molecular and Rayleigh scattering, after the gas absorption contribution has been factored out: $\rho_{\mathrm{c}}$ the intrinsic atmospheric reflectance, also called atmospheric path reflectance; $S_{\mathrm{c}}$ the spherical albedo, the reflectance of the atmosphere for isotropic light entering it from the surface; $e^{-\tau / \mu_{0}}$ and $t_{\mathrm{d}}\left(\mu_{0}\right)$ are the downward direct and diffuse transmittances of the atmosphere along the path of the incoming solar beam; $e^{-\tau / \mu_{v}}$ and $t_{\mathrm{d}}\left(\mu_{\mathrm{v}}\right)$ are the upward transmittances of the atmosphere in the viewing direction. The other terms describe surface properties: $\rho_{\mathrm{s}}$ is the surface reflectance; $\rho_{\mathrm{hd}}, \rho_{\mathrm{dh}}$, and $\rho_{\mathrm{hh}}$ are the surface hemispherical-directional, directional-hemispherical, and hemispherical-hemispherical reflectances, respectively.

These latter terms are also called coupling terms, as they couple atmospheric radiative transfer with the surface reflectance (United States National Bureau of Standards and Nicodemus 1977; Schaepman-Strub et al. 2006). For the remote sensing situation, they are defined as:

$$
\begin{gathered}
\rho_{\mathrm{hd}}=\frac{\int_{0}^{2 \pi} \int_{0}^{1} \mu L_{\downarrow}\left(\mu_{0}, \mu, \phi^{\prime}\right) \rho_{\mathrm{s}}\left(\mu_{0}, \mu_{v}, \phi^{\prime}-\phi\right) \mathrm{d} \mu \mathrm{d} \phi^{\prime}}{\int_{0}^{2 \pi} \int_{0}^{1} \mu L_{\downarrow}\left(\mu_{0}, \mu, \phi^{\prime}\right) \mathrm{d} \mu \mathrm{d} \phi^{\prime}} \\
\rho_{\mathrm{dh}}\left(\mu_{0}, \mu_{\mathrm{v}}, \phi\right)=\rho_{\mathrm{hd}}\left(\mu_{\mathrm{v}}, \mu_{\mathrm{v}}, \phi\right) \\
\rho_{\mathrm{hh}}=\rho_{\mathrm{dh}}\left(\mu_{0}, \mu_{\mathrm{v}}, \phi\right) \simeq \frac{\int_{0}^{1} \int_{0}^{2 \pi} \int_{0}^{1} \rho_{\mathrm{s}}\left(\mu, \mu^{\prime}, \phi\right) \mu \mu^{\prime} \mathrm{d} \mu^{\prime} \mathrm{d} \mu \mathrm{d} \phi}{\int_{0}^{1} \int_{0}^{2 \pi} \int_{0}^{1} \mu \mu^{\prime} \mathrm{d} \mu^{\prime} \mathrm{d} \mu \mathrm{d} \phi}
\end{gathered}
$$

where $L_{\downarrow}\left(\mu_{0}, \mu, \varphi^{\prime}\right)$ is the downward diffuse irradiance from the Sun at $\mu_{0}$. Equations 2 and 3 can be computed exactly from the downward radiation, whereas Eq. 4 (involving at least two interactions between the atmosphere and the surface) is typically approximated by taking $\rho_{\text {hh }}$ equal to the hemispherical albedo of the target. Multiple scattering tends to be azimuthally independent, so this approximation replaces a double integration by a single one. It is justified by the limited impact on the total signal of this last contribution.

Although Eq. 1 gives a rigorous formulation of the radiative coupling between the atmosphere and the surface, there is no closed form solution to invert surface reflectance since $\rho_{\mathrm{s}}$ is embedded in the integrals accounting for the coupling terms in Eqs. 2, 3, and 4. This can be inverted by an iterative optimization using an initial guess for $\rho_{\mathrm{s}}$ (Hu et al. 1999; Vermote et al. 1997a), but accurate guesses are seldom possible for single-view (as opposed to multi-angular) remote sensing. Assume that a Lambertian reflectance is often more practical for operational atmospheric correction. No real surface shows perfect Lambertian behavior, but many can be represented with this approximation to a reasonable extent. Under the Lambertian assumption,

$$
\rho_{\mathrm{hd}}=\rho_{\mathrm{dh}}=\rho_{\mathrm{hh}}=\rho_{\mathrm{s}}
$$

Equation 1 becomes:

$$
\rho_{\text {toa }}^{*}=T_{\mathrm{g}}\left[\rho_{\mathrm{a}}+\frac{T_{\mathrm{d}} T_{\mathrm{u}} \rho_{\mathrm{s}}}{1-S \rho_{\mathrm{s}}}\right]
$$


in which the angular and spectral dependencies of the different terms are omitted and $T_{\mathrm{d}}$ and $T_{\mathrm{u}}$ represent the total downward and upward transmittance (for direct + diffuse radiation), respectively. The atmospheric optical parameters and $\rho_{\mathrm{s}}$ are decoupled in Eq. 6, so a simple expression for $\rho_{\mathrm{s}}$, which is now a Lambertian-equivalent surface reflectance, can be derived analytically:

$$
\hat{\rho}_{\mathrm{s}}=\frac{\rho_{\text {toa }}^{*} / T_{\mathrm{g}}-\rho_{\mathrm{c}}}{T_{\mathrm{c}}+S_{\mathrm{c}}\left(\rho_{\text {toa }}^{*} / T_{\mathrm{g}}-\rho_{\mathrm{c}}\right)}
$$

Some care is required with the gas absorption $T_{\mathrm{g}}$. Gas absorption features manifest at spectral resolution much higher than the typical VSWIR imaging spectrometer. To simulate a radiance measurement, it is typically necessary to calculate these terms at a very high spectral resolution prior to sampling by the instrument response function. Figure 2 illustrates a typical instantiation of $T_{\mathrm{t}}$, the transmittance due to atmospheric gases, after sampling by the instrument response function. Annotations attribute features to different atmospheric constituents. An alternative to calculating $T_{\mathrm{g}}$ at high spectral resolution is to treat each band as a distribution of magnitudes with different populations, an approach known as the correlated $k$ method (Fu and Liou 1992). The remaining terms are spectrally smooth and can be calculated at a coarser resolution. This decoupling is accurate in situations where scattering is weak.

The approach of decoupling gas absorption from gas and particle scattering may not be accurate in wavelengths with strong gaseous absorptions, or where scattering is strong, but the simplifications in the equations and the subsequent saving in computation time make useful efficient radiative transfer calculations in the VSWIR spectral range. A similar formulation which does not assume decoupling between atmospheric absorption and scattering can be written simply as:

$$
\rho_{\mathrm{toa}}^{*}=\frac{L_{\mathrm{obs}} \pi}{\mu_{o} F_{o}}=\rho_{\mathrm{a}}+\frac{T \rho_{\mathrm{s}}}{1-S \rho_{\mathrm{s}}}
$$

This defines $T$ to be the transmittance including both scattering and gas absorption components along the Sun-sensor path. Similarly, $\rho_{\mathrm{a}}$ and $S$ represent the atmospheric reflectance and spherical albedo incorporating the coupled effects of gas absorption. The corresponding target reflectance estimate is:

$$
\hat{\rho}_{\mathrm{s}}=\frac{1}{T /\left(\rho_{\text {toa }}^{*}-\rho_{\mathrm{a}}\right)+S}
$$

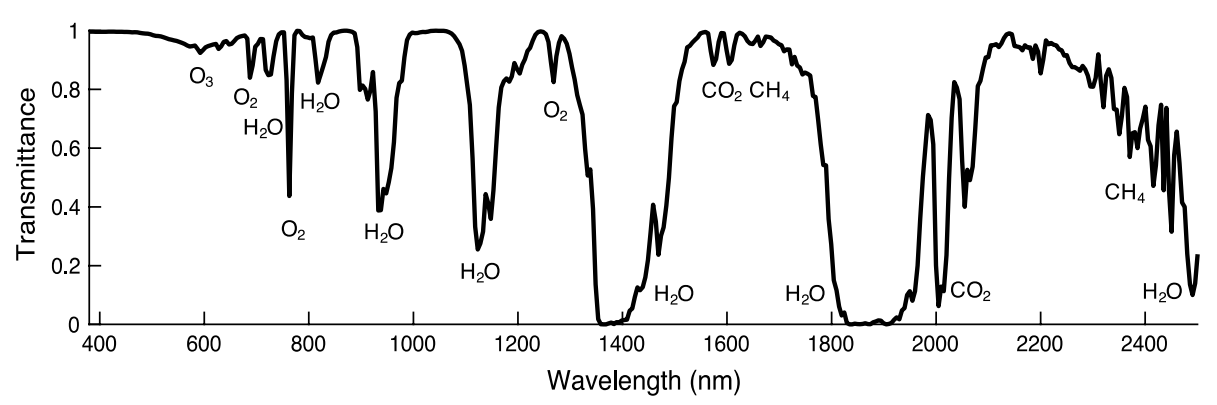

Fig. 2 Atmospheric transmittance due to gas absorption, $T_{\mathrm{g}}$, as a function of wavelength 
Note that in the coupled model, $S, T$, and $\rho_{\mathrm{a}}$ include spectrally sharp gas absorption features and must be calculated at high spectral resolution or with correlated $k$.

In practice, the quantities described thus far are calculated using radiative transfer codes such as 6S (Vermote et al. 1997b) or DISORT (Stamnes et al. 1988), the core of MODTRAN (Berk et al. 2016). These solvers propagate the solar flux at the top of atmosphere along the proper geometric path through an altitude-stratified atmospheric model populated with appropriate gas and particle abundances. The solver calculates diffuse and direct fluxes at each layer, accounting for absorption and scattering. Any of the above quantities that cannot be directly calculated in this fashion can be found from multiple runs of the radiative transfer code for a handful of different constant surface albedo values. For example, $\rho_{\mathrm{s}}=0$ provides the path radiance, and two additional albedos (e.g., 0.5 and 1.0) give a system of equations with closed form solutions for $T$ and $\mathrm{S}$.

\section{Retrieval of Atmospheric Parameters and Surface Reflectance}

The atmosphere changes on relatively short spatial and temporal timescales, so some constituents must be estimated from the measurement data. Contemporary codes differ in their parameterizations and inversion methodology. This section describes approaches for retrieving atmospheric state variables such as the pressure altitude (Thompson et al. 2015a, 2018a), water vapor (Gao and Goetz 1990; Schläpfer et al. 1998), and aerosol parameters (Gao et al. 2000; Guanter et al. 2007). We also show methods for post-processing reflectance data to account for surface Bidirectional Reflectance (Schläpfer et al. 2015) and other effects.

\subsection{Pressure Altitude}

The dominant source of spatial variability in the atmosphere is the vertical depth of the column. Pressure altitude describes the effective surface pressure experienced by photons transecting the atmosphere along the instrument's optical path from Sun to ground to sensor. The pressure altitude is mostly a function of surface topography and is generally close to the altitude of the surface under nominal barometric conditions. The pressure altitude influences absorption and Rayleigh scattering by well-mixed gases, so it is important for both the transmittance and path radiance terms of Eq. 1. Most atmospheric correction routines either obtain pressure altitude directly from a digital elevation model (DEM) or use a single presumed elevation everywhere when the scene is flat. However, it is also possible to retrieve the pressure altitude from the data itself, which may be a more accurate estimate of the optical path under the precise scattering conditions of the acquisition.

Most strategies for retrieving pressure altitude rely on the depth of the oxygen A band feature. The continuum interpolated band ratio or CIBR (Green et al. 1989; Bruegge et al. 1990) measures the depth of the absorption feature relative to a linear continuum. One can easily estimate the continuum by interpolating linearly across the feature from the extremes. Green et al. (1993) and Thompson et al. (2015a) use the CIBR approach for pressure altitude estimation, improving accuracy over scenes with topographic variability. Oxygen band depths are also influenced by aerosol scattering (via the additive path radiance term), so this retrieval method tends to work best under strong aerosol constraints. 


\subsection{Column Water Vapor}

Absorption by water vapor is another major source of spatial variability in measured radiances. It is common to use near-infrared water vapor absorption bands at 820, 940, or $1130 \mathrm{~nm}$ for columnar water vapor retrieval (Fig. 3). The optimal spectral region depends on the sensor characteristics and the absolute humidity of the atmosphere. While highquality, full spectral range imaging spectrometers offer flexibility in choosing the spectral range, the choice is limited to the $820 / 940 \mathrm{~nm}$ range for visible and near infrared (VISNIR) spectrometers and may even be restricted further to $820 \mathrm{~nm}$ by calibration accuracy. The $820 \mathrm{~nm}$ range, on the other hand, bears the problem that it shows lower absorption. This may be critical when processing imagery with low water vapor content. Two common methods for water vapor retrieval are differential absorption methods using relative absorption strength (Schläpfer et al. 1998) and curve fitting techniques (Gao and Goetz 1990).

In the differential absorption approach, the water vapor amount is related to relative depth of the absorption feature as calculated by a two- or three-channel band ratio (Bruegge et al. 1990). However, this relation varies depending on the additive effect of aerosol scattering. The atmospheric pre-corrected differential absorption (APDA, Schläpfer et al. 1998) technique uses a terrain dependent correction of the atmospheric path radiance term before the apparent transmittance values are related to total columnar water vapor. A radiative transfer code like MODTRAN is used to calculate the spectral path radiance and to find an exponential conversion function between transmittance and water vapor amount for the atmospheric conditions of a specific scene. The APDA technique reduces the errors due to background reflectance variations significantly compared to differential absorption techniques based on top of atmosphere (TOA) radiance. Validation of the results in comparison with water vapor contents derived from AERONET has shown an RMSE accuracy of 0.12cm column water vapor (Makarau et al. 2017).

Spectral curve fitting is an alternative that leverages the full spectroscopic measurement, matching the shape of the $\mathrm{H}_{2} \mathrm{O}$ absorption feature (Gao and Goetz 1990; Thompson et al. 2015a) over a spectral interval bracketing it. For example, Gao and Goetz (1990) calculate a water vapor absorption with a full radiative transfer model and then
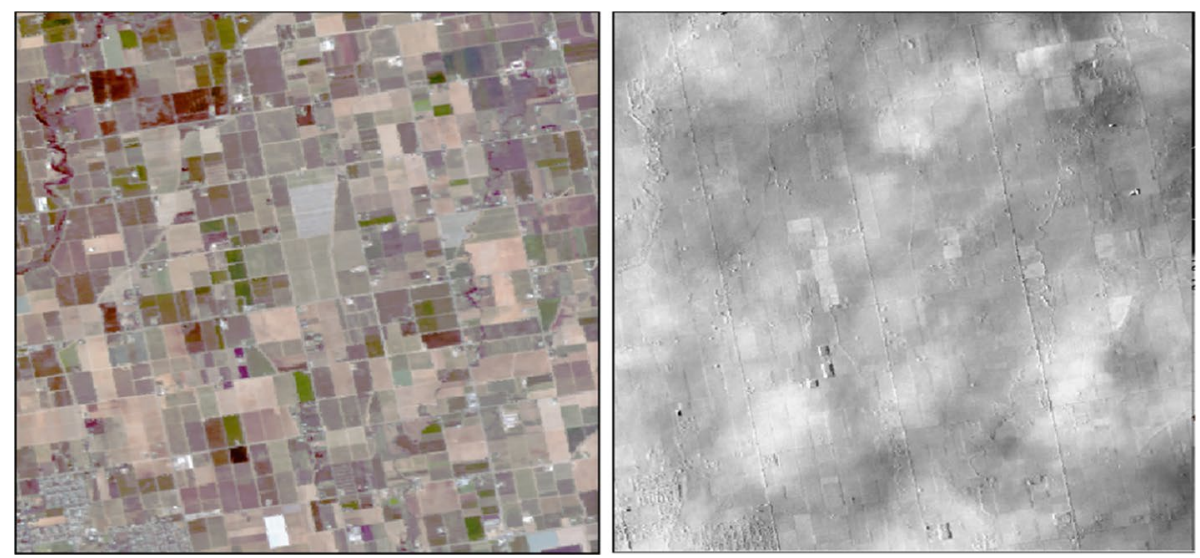

Fig. 3 (left) An image from the Airborne Visible Infrared Imaging Spectrometer (AVIRIS-C), visible channels. (right) Corresponding map of atmospheric water vapor retrieved using the spectrum fitting technique in Thompson et al. (2015a) 
estimate a linear scaling that best fits the absorption feature in TOA spectra. To avoid indeterminacy, most such methods model surface reflectance in this short interval as a linear slope. The coefficients can be retrieved as free parameters in a joint optimization or estimated directly by interpolating across the top of the absorption feature.

In reality, the reflectance is never a perfect linear continuum; more complex surface reflectance shapes can distort both ratios and spectral fits. Liquid water and ice are common offenders, since they are pervasive in snow and tree canopies and have absorption features overlapping with those of vapor. To remedy this, Gao and Goetzt (1995) jointly fit liquid and vapor, treating them as Beer-Lambert absorptions that are log-linear in the path lengths. A similar assumption holds (approximately) for the continuum over short spectral intervals, allowing all parameters to be fit simultaneously as a linear equation mapping path length and reflectance parameters to the negative log TOA reflectance. Thompson et al. (2015a) adopted a similar approach while constraining the retrieved parameters to be nonnegative. In both cases, the water vapor parameter is not perfectly log-linear at typical imaging spectrometer resolutions due to under-resolved spectrally fine structure. This necessitates an initial guess derived from band ratio methods to determine an "effective" absorption coefficient. Green et al. (2006) used a nonlinear fit to match the vapor feature more accurately at the cost of additional computational complexity. They pre-calculate transmittance lookup tables at many different water vapor concentrations and match measured radiances using nonlinear least squares optimization. In both linear and nonlinear cases, fitting atmosphere and surface simultaneously improved accuracy vis-a-vis a linear reflectance continuum.

Figure 4 shows an example of such approaches applied to a mosaic by the "Classic" Airborne Visible InfraRed Imaging Spectrometer (AVIRIS-C) over Yosemite National Park on May 2013. Color channels indicate water in different phases: Blue represents water vapor, which fills topographic lows; green represents liquid water at the surface, which is present mainly in tree canopies; and red represents ice, which is present as melting snow at high elevations and appears yellow due to coincidence with the liquid phase.
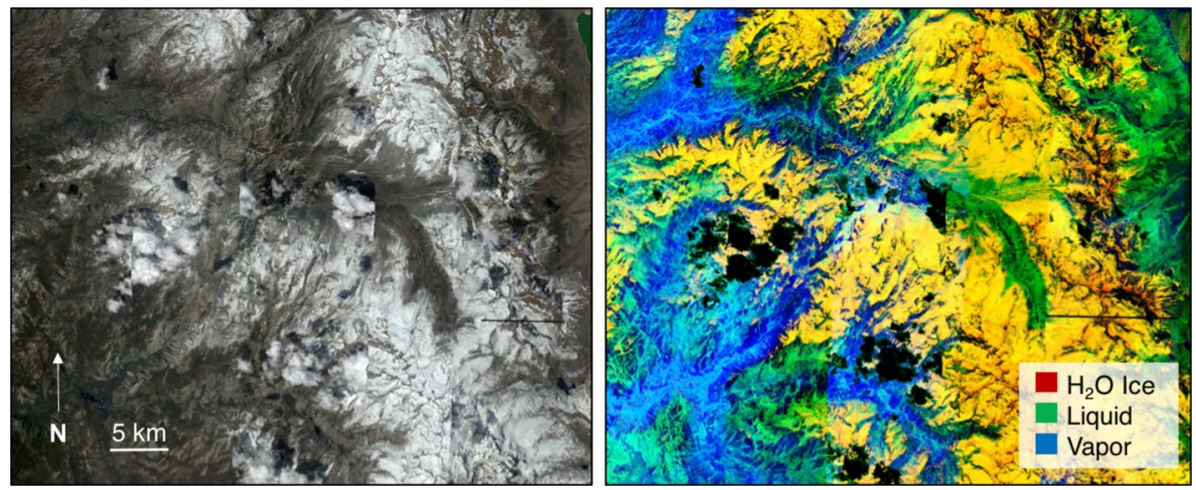

Fig. 4 Three phases of water apparent in an AVIRIS-C mosaic of flightlines over Yosemite National Park. (left) Mosaic in visible wavelengths. (right) Abundance of water phases. Blue represents $\mathrm{H}_{2} \mathrm{O}$ vapor, green is liquid water in vegetation canopies, and red represents ice. Yellow areas are a combination of liquid and ice, i.e., melting snow. Black areas have no data, due mainly to clouds and cloud shadows 


\subsection{Ozone}

Apart from oxygen and water vapor, other gases play a role in the visible shortwave infrared interval. Methane, carbon monoxide, nitrous oxide, and carbon dioxide all have absorption features in this range (Gao et al. 1993). However, most of these gas concentrations are sufficiently predictable that dynamic estimation is not usually needed to determine surface reflectance. For example, accurate VSWIR surface reflectance retrieval must account for ozone in the 450-800-nm spectral region, which has a peak absorption (minimum transmittance) around $600 \mathrm{~nm}$. Typically, ozone column information (in Dobson Units, or DU) is drawn from external sources, e.g., ozone-measuring instruments such as TOMS, GOME, OMI or numerical weather predictions, e.g., the National Center for Environmental Prediction (NCEP) or the European Center for Medium-Range Weather Forecasts (ECMWF). Contrary to aerosol and water vapor variations, ozone concentrations usually change slowly on a monthly scale; typical variations are 50-100 Dobson Units (DU), typical spatial changes are on a grid of $1^{\circ}-5^{\circ}$, i.e., about 100-500 km (Loyola et al. 2009). If the ozone column is known, then the ozone gas transmittance can be calculated with a knowledge of the spectral absorption coefficient and solar/view geometry (Yamamoto et al. 2008). Another approach for ozone correction is based on lookup tables derived from radiative transfer calculations (Richter et al. 2014) covering the relevant solar and view geometries and a range of ozone columns (e.g., 200-600 Dobson Units).

\subsection{Atmospheric Aerosols and Haze}

Unlike water vapor features that show distinctive spectral shapes over narrow intervals, atmospheric aerosols and haze induce spectrally smooth perturbations that can be difficult to disentangle from legitimate changes in surface reflectance. There are many methods to estimate the aerosol scattering and haze distribution from imaging spectroscopy data, and no universal standard has yet emerged. One may distinguish between methods that rely on known reflectance spectra from reference surfaces, statistical approaches, climatologydriven approaches, and radiative transfer approaches.

Reference surface methods exploit known reflectance properties for one or more locations in the scene, optimizing aerosol optical properties to match the target. Historically investigators have used a wide range of reference surface types. One of the first involved dark objects (Tanré et al. 1983). The result can be strongly affected by the surface reflectance characteristics since not all scenes contain good quality dark spectra. The dark dense vegetation approach (DDV) is an established method that exploits the reliable reflectance shape and magnitude of dense vegetation in visible wavelengths (Kaufman and Sendra 1988; Kaufman et al. 1997). Because vegetation is pervasive over much of Earth's surface, this method has been largely successful and has been incorporated in automatic atmospheric compensation routines. However, it fails when pure vegetation pixels are not present. Guanter et al. (2008) overcame this challenge with a mixture model that captures partially vegetated spectra. They use combinations of library spectra to span a subspace of legitimate reflectances. Other measures are necessary for aquatic scenes (Gao et al. 2000) where investigators can exploit the known shape of water-leaving reflectance in infrared wavelengths. If the water is deep and not too turbid, the infrared reflectance should be zero after accounting for spectrally smooth effects of aerosols and sun glint. When no nearby 
vegetation or deep clear water is available, satellite reference information from MODIS or similar instruments is another alternative (Hagolle et al. 2015).

Statistical methods are an efficient way to deal with high aerosol load and haze situations. One example employs the haze optimized transform (HOT, Zhang et al. 2002). Another uses the haze thickness map, or HTM (Makarau et al. 2014). This statistical dehazing can be performed on at-sensor radiance data as an optional pre-processing to the physical atmospheric compensation. The HTM method is an advanced locally adaptive dark-object subtraction algorithm which uses statistical methods to derive the spatial haze distribution. It treats the aerosol contribution as an additive path radiance term raising the "zero point" of the radiance spectrum. Because this term varies over the image, a local subwindow search for dark pixels estimates the haze contribution separately at each location and band in the scene.

Despite progress on these fronts, aerosol correction remains a challenging atmospheric correction problem in the general case. Methods that work well in isolated test cases may fail if their assumptions are violated, such as in scenes lacking dark pixels or aerosols with unexpected optical absorption properties. Aerosol correction can also suffer under very hazy conditions where particle scattering modifies the optical path length, changing the shape of gas absorption features and contaminating other gas retrieval and correction. To address these shortcomings, recent research has focused increasingly on methods that incorporate rigorous radiative transfer modeling. One is an iterative approach to derive aerosol amounts over dark objects and shaded areas (c). The atmospheric compensation method itself is used for the aerosol amount inversion by evaluating the brightness of corrected cast shadow areas in comparison with directly illuminated regions. A precondition to this method is the presence of shaded pixels, which are most abundant in images with spatial sampling finer than $10 \mathrm{~m}$. Another radiative transfer approach uses sophisticated surface models to estimate the joint probability of different aerosol/surface combinations given the remote measurement; Bayesian formalisms can incorporate prior climatology and surface expectations with remote data to determine the full posterior distribution (Frouin and Pelletier 2015).

\subsection{Cirrus}

A unique challenge of high altitude and orbital observations is frequent contamination by thin cirrus clouds. Fortunately, the VSWIR interval permits effective correction algorithms (Makarau et al. 2016). Through analysis of high-altitude AVIRIS-C data, Gao and Kaufman demonstrated that narrow channels within the 1.38- and $1.88-\mu \mathrm{m}$ atmospheric band centers are very effective in detecting thin cirrus clouds (Gao and Kaufman 1995). In the absence of cirrus clouds, channels near $1.38 \mu \mathrm{m}$ receive little scattered solar radiance by the surface and the low-level water clouds because of the total absorption of solar radiation by atmospheric water vapor above them. When cirrus clouds are present, these channels receive scattered solar radiance by the cirrus clouds, which contrast well on the nearly black background. However, the 1.38 - $\mu$ m channels are slightly affected by absorption from water vapor located above and within thin cirrus clouds. These effects must be removed in order to use the $1.38-\mu \mathrm{m}$ signal for quantitative cirrus correction in other channels (Gao et al. 1998, 2002).

For thin cirrus, one can model the cloud as a homogeneous layer located above a "virtual surface," which includes the effects of Rayleigh scattering and land or ocean surface reflection and scattering. Accounting for transmission through the cirrus cloud 
and multiple reflections between cloud and the "virtual surface," we have the following relationship (similar to what is done for aerosol correction, e.g., Fraser and Kaufman 1985):

$$
\rho_{\text {toa }}^{*}=\rho_{\mathrm{i}}+\frac{T_{\mathrm{i}} \rho_{\mathrm{v}}}{1-S_{\mathrm{i}} \rho_{\mathrm{v}}}
$$

where $\rho_{\mathrm{i}}$ is the reflectance of the cirrus (ice) cloud, $T_{\mathrm{i}}$ is the two-way transmission (direct+diffuse) through the cloud, $\rho_{\mathrm{v}}$ is the reflectance of the "virtual surface," and $S_{\mathrm{i}}$ is the cloud-base reflectance of upward radiation. Because $S_{\mathrm{i}} \rho_{\mathrm{v}} \ll 1$ for thin cirrus, the equation can be simplified to:

$$
\rho_{\text {toa }}^{*}=\rho_{\mathrm{i}}+T_{\mathrm{i}} \rho_{\mathrm{v}}
$$

In order to remove the cirrus effect from the satellite measurement $\rho_{\text {obs }}$, namely to derive $\rho_{\mathrm{v}}$, cirrus reflectance $\rho_{\mathrm{i}}$ and transmittance $T_{\mathrm{i}}$ must be known. Through analysis of AVIRISC data, Gao et al. (1998) found that cirrus reflectance $\rho_{\mathrm{i}}$ for channels between 0.4 and $1.0 \mu \mathrm{m}$ was linearly related to $\rho_{\mathrm{i}}$ at $1.375 \mu \mathrm{m}$, i.e.,

$$
\rho_{i}=\rho_{i}(1.375 \mu \mathrm{m}) / \mathrm{K}, \quad 0.4<\lambda<1.0 \mu \mathrm{m}
$$

where $K$ is an empirical parameter derived from data. It is essentially the $1.375-\mu \mathrm{m}$ channel transmittance for water vapor above and within cirrus clouds. The weak ice absorption at $1.375 \mu \mathrm{m}$ also slightly reduces the $K$ value. Algebraic substitution gives:

$$
T_{i} \rho_{v}=\rho_{\text {toa }}^{*}-\rho_{i}(1.375 \mu \mathrm{m}) / \mathrm{K}, \quad 0.4<\lambda<1.0 \mu \mathrm{m}
$$

The image of $T_{\mathrm{i}} \rho_{\mathrm{v}}$ is referred to as the "cirrus-path-radiance-corrected" image. It is similar to the "virtual surface" reflectance image of $\rho_{\mathrm{v}}$ due to high transmittance of thin cirrus clouds ( $\mathrm{T}_{i}$ is usually greater than 0.9 ).

In order to use the 1.38-micron channels for quantitative correction of thin cirrus effects in other channels, one must account for the absorption by water vapor above and within cirrus clouds. The water vapor transmittance factor, $K$, can be obtained from a scatter plot between the 1.38- $\mu \mathrm{m}$ channel and a channel in atmospheric window region, such as $1.25 \mu \mathrm{m}$. The minimum value of $\rho_{\text {obs }}$ at $1.25 \mu \mathrm{m}$ for each possible value of $1.38 \mu \mathrm{m}$ is a slope that estimates $K$ (Gao et al. 1998). An empirical algorithm for the derivation of cirrus reflectances has already been implemented for processing MODIS data (Gao et al. 2002). This would also estimate thin cirrus reflectances in the $0.4-1.0 \mu \mathrm{m}$ region using the empirically derived $K$ value in the equation above, permitting cirrus correction in wavelengths shorter than $1 \mu \mathrm{m}$.
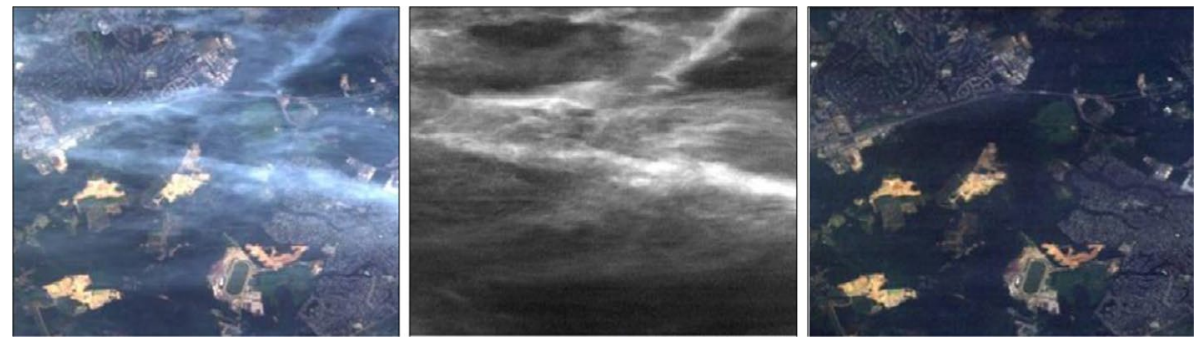

Fig. 5 Left: An AVIRIS-C red/green/blue (RGB) image acquired over Bowie, Maryland in July 1997. Center: The 1.38- $\mu \mathrm{m}$ image. Right: the cirrus-corrected RGB image 
Figure 5 shows examples of cirrus detection and corrections with a narrow channel located within the strong water vapor absorption region near $1.38 \mu \mathrm{m}$. The left panel shows visible wavelengths of an AVIRIS-C image acquired over Bowie, Maryland in the summer of 1997. Surface features appear blurred because of the presence of thin cirrus clouds. The center panel is the 1.38- $\mu \mathrm{m}$ channel image of the same scene. Only the upper level thin cirrus clouds are seen. The surface features seen in the left panel disappear completely in the center because of absorption of water vapor beneath cirrus. The right panel is the cirruscorrected RGB image. The corrections were made using the procedures outlined above. Comparing left and right panels illustrates that removing thin cirrus improves contrast in the surface features.

\subsection{Bidirectional Reflectance Distribution Function (BRDF) Retrieval and Compensation}

The output of atmospheric compensation is typically described as bottom of atmosphere (BOA) reflectance and is also often referred to as hemispherical conical reflectance factor (HCRF) or hemispherical directional reflectance factor (HDRF) (Schaepman-Strub et al. 2006). This represents the fractional reflectance of the hemispherical incident illumination onto the surface, sampled in the direction of the sensor. However, as noted in the original coupled BRDF-atmosphere formulation of Eq. 1, the reflectance is never perfectly isotropic. In fact, the sensor direction is just one sample of a richer Bidirectional reflectance distribution function, or BRDF, which describes how reflectance changes for different incidence and observation angles. The BRDF captures specular properties like glint and can be used at larger ground sampling distances to represent geometric effects from surface faceting and cast shadows.

According to United States National Bureau of Standards and Nicodemus (1977), the HCRF and HDRF are defined with respect to a complete, full-sky illumination field which is not the natural remote sensing situation. Accounting for location-specific illumination effects such as obscuration can help retrieve values close to a physical HDRF as intermediate output of atmospheric compensation. This involves correcting for topographic illumination and incidence BRDF effects. Still stronger bidirectional reflectance effects occur in the observation direction for off-nadir viewing. If the application desires an observation-independent quantity, one can transform the HDRF to an equivalent nadir-perspective measurement by accounting for the BRDF of each pixel.

The BRDF Effects Correction method BREFCOR (Schläpfer et al. 2015) uses the RossThick-Li-Sparse (RTLS) reciprocal BRDF model. The model is tuned to the surface cover properties based on a continuous BRDF cover characterization index (BCI). This allows a surface cover dependent but yet continuous correction of the HDRF to bihemispherical reflectance (BHR), i.e., to the spectral albedo. The method is of generic nature and has been successfully applied to 4-band photogrammetric imagery, to multispectral space borne multi-angle imagery, and to airborne imaging spectroscopy data (Schläpfer et al. 2015).

\subsection{Topographic Corrections}

A presentation of atmospheric correction techniques would be incomplete without at least mentioning the problem of topographic correction. Surface topography affects imaging spectroscopy in several ways. At a coarse level, the surface elevation defines the bottom 
of the atmospheric column, influencing the amount of scattering and absorption by gases and aerosols; this is the subject of Sect. 3.1 above. This section deals with subtler effects related to the influence of local slope and topography on the incident light field. An adequate discussion of the available methods is out of scope for this work, so we restrict our treatment to the main challenges and some state-of-the-art solutions. In common to all topographic correction methods is the correction of the varying illumination field for each pixel based on the local description of the topography. This correction may be achieved by physical modeling (Teillet et al. 1982; Sandmeier and Itten 1997; Li et al. 2015). Or by empirical and semi-empirical approaches (Kobayashi and Sanga-Ngoie 2008; Soenen et al. 2005; Riano et al. 2003), commercially available codes for the inversion of atmospheric parameters of imaging spectrometers are ACORN (www.aigllc.com) ATCOR (www.reseapps.com), FLAASH (www.harrisgeospatial.com), but only ATCOR includes an option for topographic compensation (Richter 1998).

In rugged terrain, a Digital Elevation/Surface Model (DEM/DSM) defines the elevation map for the imaging spectrometer scene. The elevation map is resampled to obtain the elevation on a per-pixel level, and then the slope and aspect maps have to be calculated. Critical issues are the adequate spatial resolution of the DEM (at least comparable to the pixel size of the scene) and the accuracy of the DEM itself. For steep terrain but also for high spatial resolution data, the maps of sky view factor (portion of visible sky dome per pixel) and topographic shadow (self and cast shadow from surrounding obstacles) are required. In shadow regions, the direct solar irradiance is zero, and even the diffuse solar flux (due to scattered radiation) is reduced according to a sky view factor. This makes an atmospheric inversion extremely difficult, especially for low-radiometric-resolution instruments (8-10 bit/pixel). Even for a 12-16-bit dynamic range, the correction of shadow areas is difficult causing over- and under-correction artifacts. A shadow fraction parameter can be introduced based on blue/green and blue/red radiance ratios to better estimate the diffuse illumination caused by scattering (Schläpfer et al. 2013). This shadow fraction improves the illumination map calculated from the DEM. Finding accurate DEM/DSMs is difficult for very high-resolution $(<10 \mathrm{~m})$ data; at the time of this writing, freely available global DEMs have a spatial resolution up to $30 \mathrm{~m}$ (e.g., ASTER 2018, SRTM 2018). Better DEMs and DSMs may become available in the future, but their better resolution will not always be sufficient to describe the underlying physics in the case of forests or vegetation canopies.

Even for moderately steep terrain (pixel slope values of $10^{\circ}-20^{\circ}$ ) spatially varying topographic effects often dominate over atmospheric effects. Despite the illumination effects, directional effects of surface reflectance play a strong role, i.e., even for nadir-looking sensors any terrain changes of surface slope and orientation cause significant changes of the recorded radiance (Shepherd and Dymond 2003; Richter et al. 2009). In addition to the adjacency effect, one often considers the radiation reflected from facing surfaces, such as mountains or buildings within the line-of-sight of each pixel. In the ideal case, the incidence BRDF for each pixel is required. However, per-pixel knowledge of the incidence BRDF (distinct from the "observer BRDF" of Sect. 3.6) is scarce for very high-resolution imagery. Li et al. (2015) approximated this problem by spatially resampling incidence BRDF functions calculated from MODIS scenes, i.e., using 500-m incidence BRDF data on a 30-m raster. This leaves the effect of observation angle uncorrected. For the compensation of BRDF effects, one may use a global incidence BRDF model derived from MODIS data or one can try to fit the best-suited model to the given data and observation angles (Jensen et al. 2018). 


\subsection{Spectral Polishing}

As the spectral resolution of imaging spectrometers has gradually improved with time, spectral artifacts have become more and more visible in the atmospherically corrected data. There are two common reasons for these high-frequency spikes (Schläpfer and Richter 2011). First, systematic deviations may be caused by inappropriate radiometric standards, by spectral miscalibration, by systematic errors in the description of the atmospheric absorption or from uncertainties in the solar reference spectrum. Non-systematic (statistical) variations may be caused by the intrinsic variation of the atmosphere and the sun, the statistical photon shot noise, or due to readout noise in the detector electronics. Investigators often correct these artifacts with system- and situation-specific techniques known colloquially as spectral polishing (Boardman 1998; Gao and Liu 2013). The term can be defined as the removal of statistical noise and calibration artifacts in the spectral domain from atmospherically corrected imaging spectroscopy surface reflectance data.

For instruments at resolutions in a range of 10-30 nm, systematic errors are most prominent. One can correct such errors by searching for systematic deviations from average of each detected pixel, using flat field or empirical line analysis. Such corrections implicitly correct solar spectrum uncertainties which are relevant at the scale of 5-10 nm (Gao et al. 2009). In certain aquatic applications, uncertainties in the solar spectrum, and the instruments' sampling thereof, persist because they distort radiances rather than reflectances-if the path radiance is a large fraction of the measured signal, then solar-related systematic errors will not be multiplicative after the conversion to reflectance. In such cases, it is possible to optimize the solar spectrum directly based on spectrally smooth reference targets (Thompson et al. 2015c).

With the advance of high-resolution pushbroom-type imaging spectrometry systems, statistical variations can also be prominent. Investigators often use statistical strategies to correct these deviations. This exploits the fact that for many applications in the VSWIR range, surface reflectance signatures do not show important variability at resolutions below $10 \mathrm{~nm}$. Such applications include general water quality studies, hydrology studies of snow and ice, basic mineralogical analyses and some terrestrial and aquatic ecosystem investigations. Here, the criterion of a "good" spectrum at resolutions below $10 \mathrm{~nm}$ is its smoothness in the spectral space. Filtering may be done by straight forward smoothing algorithm, Savitzky-Golay filters, derivative filters, or Fourier transform filtering. Schläpfer and Richter (2011) find that derivative filters or Savitzky-Golay filters perform best in reconstructing a spectrum affected by statistical noise. Other applications, such as mapping of subtle mineralogical distinctions, canopy chemistry or species discrimination (Kokaly et al. 2009), or discrimination and detection of anthropogenic materials, benefit from higher spectral resolution. Investigators are often cautious about deploying statistical polishing in these domains.

\section{Uncertainties in Atmospheric Correction}

This section describes uncertainties in VSWIR atmospheric correction for global imaging spectrometers. We begin by reviewing prior studies and some established strategies for field validation. Then, a simulation demonstrates the sensitivity of typical aquatic and terrestrial ecosystem analyses to atmospheric state estimation errors. 


\subsection{Empirical Uncertainty Analysis}

Countless prior field studies have compared in situ reflectance measurements against remote airborne retrievals; these give an empirical picture of typical errors. Most field studies find that, excluding BRDF post-processing or topographic treatment, different algorithmic packages typically provide broadly similar results with some minor differences in the atmospheric state retrieval (Kruse 2004). Errors hinge mainly on local atmospheric conditions, manifesting as slight slope differences or offsets related to scattering profiles with sharper residuals around atmospheric absorptions. Current methods often achieve error better than $1-2 \%$ in absolute reflectance for aquatic environments, where the surface variability is a small fraction of total radiance (Thompson et al. 2015b). Such accuracy is also regularly achieved for uniform terrestrial validation sites under clear skies.

Figure 6 shows one example from a validation experiment over Ivanpah Playa conducted on March 23, 2017. Here, NASA's Next Generation Airborne Visible Infrared Imaging Spectrometer (AVIRIS-NG) overflew a bright playa onboard a high-altitude ER-2 aircraft at $19.8 \mathrm{~km}$, which is above the majority of atmospheric absorption and scattering and therefore comparable to the orbital case. Simultaneous reflectance spectra were acquired with in situ instruments deployed by a ground team. The right panel compares the in situ data to the remote retrieval. Our atmospheric correction calculates $T, S$, and $\rho_{\text {a }}$ coefficients for different atmospheric states using MODTRAN with a correlated $\mathrm{k}$ method. We then estimated atmospheric water vapor using nonlinear least squares fitting across 940- and 1140-nm intervals. The result is within 1-2\% absolute reflectance across most of the spectrum. In more unconstrained terrestrial cases, current methods commonly achieve errors within 2-5\% absolute reflectance against reference spectra (Richter and Schlaepfer 2002; Matthew et al. 2002; Kruse 2004; Thompson et al. 2015a). Critically, atmospheric correction can still recover relative reflectance shapes-particularly over short intervalswith higher fidelity, permitting accurate recognition and mapping of spectral signatures.

Other studies evaluate atmospheric impacts on downstream products. Makarau et al. (2017) compared retrieved $\mathrm{H}_{2} \mathrm{O}$ vapor profiles to AERONET ground station retrievals, showing RMSE accuracies of 0.12-cm column water vapor. Palacios et al. (2015) compared different reflectance retrievals for open water phytoplankton studies. While measurements often agreed to within 1-2\% absolute reflectance, accurate scattering compensation proved critical; subtle slope differences relate to blue-end distortions caused poor statistical
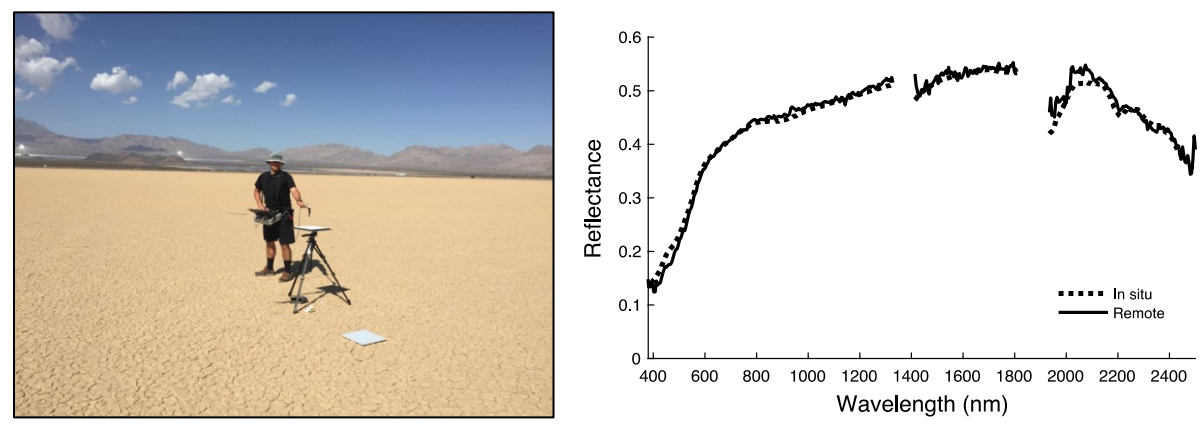

Fig. 6 In situ validation example from Ivanpah Playa by AVIRIS-NG, 23 March 2017, acquired from an ER-2 aircraft at $19.8 \mathrm{~km}$ altitude with 39.2 degrees solar elevation. Left: field procedure. Right: comparison of spectra. No spectral polishing has been applied 
correlations to chlorophyll-a retrievals for all but one of the attempted atmospheric correction strategies. Other studies demonstrate the importance of BRDFs; Weyermann et al. (2014) evaluated vegetation indices under uncorrected surface anisotropy, finding considerable variability in small-scale retrievals of band ratios. Bachmann et al. (2015) showed how both radiance and reflectance errors can influence vegetation indices measured by the EnMAP instrument.

\subsection{Simulation Method}

Here, we explore sensitivities in a simple, controlled simulation. Atmospheric correction uncertainties are influenced by factors ranging from calibration to imaging conditions to the atmosphere itself. For generality, we will limit our study in a few important respects. First, we use a generic instrument specification: a spectral range of $0.38-2.5 \mu \mathrm{m}$ sampled at $0.01-\mu \mathrm{m}$ intervals, a ground sampling distance (GSD) of $30 \mathrm{~m}$, and noise equivalent change in radiance (NEdL) on the order of $0.01 \mu \mathrm{W} \mathrm{cm}{ }^{-1} \mathrm{sr}^{-1} \mathrm{~nm}^{-1}$. This is typical for existing airborne instruments and anticipated orbital spectrometers. We will also assume appropriate corrections for cross-track non-uniformity of sensor look angle (for imaging geometry) and spectral response (for matching atmospheric features). Such corrections are well understood, and any discrepancies would be highly instrument-specific. Third, we analyze spectra independently, abstracting away from domain-specific scene structure. This simplifies the statistical interpretation but precludes a treatment of adjacency effects in heterogeneous environments like urban settings. Finally, we focus on the influence of atmospheric parameter errors on an idealized, uncoupled surface-one that is locally flat and uniform Lambertian. This is optimistic for natural scenes. However, departures and discrepancies in adjacency and BRDF are case-specific and challenging to simulate. Moreover, effects of locally non-uniform scene content become less relevant at larger pixel sizes of orbital instruments where one analyzes aggregated 30-m areas. As a consequence of these limitations, the reader should consider the resulting uncertainties as a lower bound and most appropriate for favorable surfaces and illumination at 30-m sampling. However, in this context it provides a controlled experiment to compare the sensitivity of typical investigations to the most critical atmospheric variables.

We begin with a set of reference reflectances representing two typical, representative application domains with relevant features across a wide range of wavelengths (Fig. 9). The first is a terrestrial ecosystem investigation using unmixing to determine the fractional composition of different vegetated and non-vegetated surfaces as in prior studies of forest health, invasive species, and draught. We form a reference surface using component spectra drawn from AVIRIS-NG airborne data: a green vegetation spectrum, Non-Photosynthetic Vegetation (NPV), and soil, each in 30\% fractions. This leaves an additional 10\% mixing fraction for a zero spectrum representing photometric shade. We combined these proportionally in a linear mixture model to form the "ideal" reflectance. The left panel of Fig. 7 shows the mixture model, with alternative spectra illustrating perturbations in each component. The second test case is a shallow water aquatic remote sensing scenario, relevant to inland or coastal bathymetry and water quality estimation challenges. We form a model spectrum using the HOPE parameterization of the water column (Lee et al. 1998, 1999), a model with five free parameters representing different particle concentrations and depth. We use typical values of particle backscatter, phytoplankton, and gelbstoff, and a depth of $3 \mathrm{~m}$. The bottom substrate is a sand spectrum extracted from PRISM images of beach sand. 

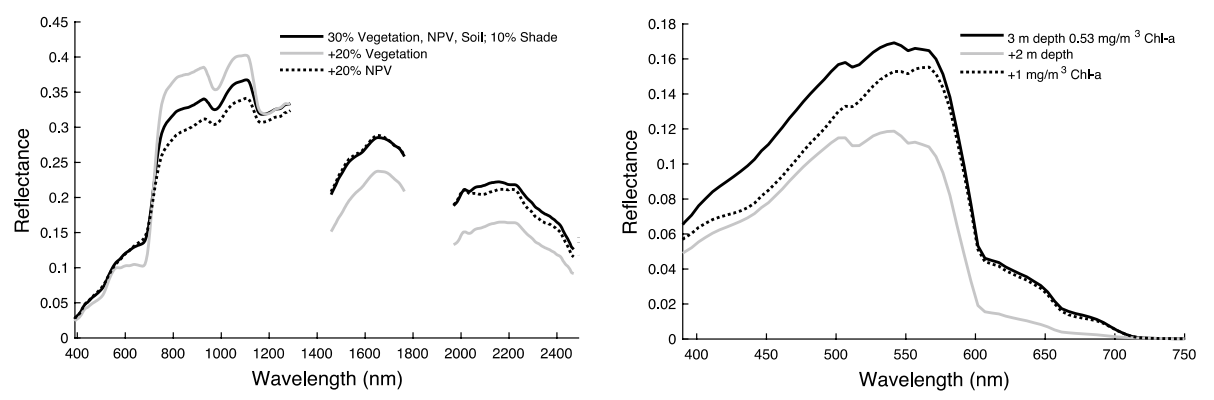

Fig. 7 Example spectra used in the sensitivity study: terrestrial (left) and aquatic (right). The dark lines show the reference cases, while the lighter lines show how different model parameters affect the spectrum shape

The right panel of Fig. 7 illustrates the result with different perturbations of the reference case.

We perform atmospheric modeling with the MODTRAN 6.0 radiative transfer code (Berk et al. 2016a, b). We begin with a nominal reference atmosphere, using the MODTRAN temperate midlatitude summer model, with $1.5-\mathrm{g} \mathrm{cm}^{-2}$ column water vapor, and thin rural aerosols providing $25 \mathrm{~km}$ of ground-level visibility. We combine this with the reference reflectances to simulate a noisy radiance measurement for a typical $30^{\circ}$ solar zenith and nadir-viewing observation. We then simulate alternative observations under perturbed atmospheres with changes in two key atmospheric parameters: aerosol scattering, including total optical depth and a categorical type representing different optical properties; and atmospheric column water vapor. We use atmospheric correction coefficients $(S$, $T$, and $\rho_{\mathrm{a}}$ ) from the nominal case to estimate the reflectance spectra under the perturbed atmosphere, to evaluate the effect of misestimating atmospheric constituents.

Finally, we retrieve geophysical variables from the resulting reflectance spectra using a handful of different techniques designed to span the relevant wavelengths and algorithm options. For terrestrial spectra we estimate NPV and green vegetation fractions by inverting the linear mixture model with the original reference spectra. We also report the estimated green fraction. In the aquatic case, we estimate bottom albedo, bathymetric depth, and chlorophyll-a concentrations by inverting the HOPE model. All numerical model inversions optimize the least squares spectrum fit of the model to the atmospherically corrected observation using a Levenberg-Marquardt solution with finite difference derivative calculations. We exclude saturated channels inside deep water vapor features at 1380 and $1850 \mathrm{~nm}$. As an alternative to these spectrum fitting methods, we also consider band ratio products based on arithmetic with just a few wavelengths. For terrestrial spectra, we calculate the Cellulose Absorption Index, or CAI, as a proxy for the NPV fraction (Nagler et al. 2003), and the Normalized Difference Vegetation Index, or NDVI, as a proxy for vegetation fraction (Carlson and Ripley 1997). In aquatic spectra, we calculate the 440-nm/670$\mathrm{nm}$ band ratio which indicates relative changes in chlorophyll-a (Cannizzaro and Carder 2006).

\subsection{Simulation Results}

Figure 8 illustrates how different perturbations of the estimated atmospheric state influence reflectance retrievals. The left and right panels show terrestrial and aquatic cases, 

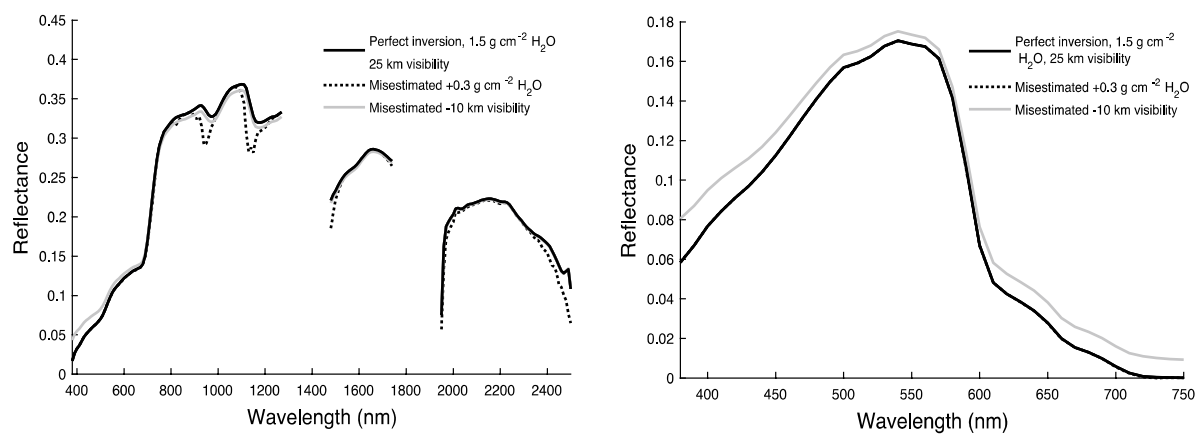

Fig. 8 Sensitivity of reflectance spectra to different atmospheric state estimation errors

respectively. Errors in columnar $\mathrm{H}_{2} \mathrm{O}$ show as localized residuals near water features at 940 and $1140 \mathrm{~nm}$ and bend the spectrum shape more generally near the deep water vapor absorptions. This slope change is most apparent in the 2000-2500-nm region that is affected by sporadic unresolved water lines. The aquatic spectra are nearly insensitive to $\mathrm{H}_{2} \mathrm{O}$ vapor. In contrast, aerosol errors modify the slope of the spectrum across the entire interval, with a difference that is most notable in short wavelengths. This suggests that many aquatic applications (such as chlorophyll retrievals in the 400-550 nm range) are highly impacted. Vegetation studies may or may not be influenced, depending on their use of visible wavelength features and their sensitivity to magnitude of the near-infrared reflectance.

Figures 9 and 10 quantify this intuition. They show how accuracy in the $\mathrm{H}_{2} \mathrm{O}$ and aerosol depth estimates propagate to the derived target quantities. Figure 9 shows error propagation from estimated $\mathrm{H}_{2} \mathrm{O}$. The aquatic applications are insensitive, while terrestrial applications show a range of different effects: calculations using NIR channels shorter than $840 \mathrm{~nm}$, such as NDVI, are relatively immune; spectrum fitting degrades gracefully with increasing $\mathrm{H}_{2} \mathrm{O}$ error; and the CAI degrades rapidly. AERONET comparisons demonstrate noise equivalent $\mathrm{H}_{2} \mathrm{O}$ sensitivities of $0.12 \mathrm{~cm}$ (Makarau et al. 2017). Extrapolating this to our reference atmosphere induces $\mathrm{a}<3 \%$ noise equivalent change in the resulting fractions. Insofar as $\mathrm{H}_{2} \mathrm{O}$ retrieval uncertainty is due to systematic modeling effects that are not visible as obvious residuals, the actual impact on the spectrum shape, and the resulting influence on derived fractions, could be smaller in practice.

Figure 10 shows the influence of atmospheric aerosol optical depth (AOD). Aquatic domains are highly sensitive to aerosols, a fact long recognized in the ocean color remote sensing community (Palacios et al. 2015). The phytoplankton algorithms, which rely on short wavelengths, are most affected. In contrast, terrestrial applications are less sensitive, with AOD errors of 0.1 producing no more than $5 \%$ change in derived variables. This is probably optimistic since it assumes the optical properties of the aerosol particles are wellcharacterized, when in practice it is difficult to know their size distribution and absorption properties. Large areas of the tropics have high aerosol optical depth, and global missions must consider these effects.

This brief study is no substitute for an investigation-specific simulation, but it underscores several key aspects of atmospheric correction. First, different domains and algorithms vary widely in their sensitivity to atmospheric state. Some algorithms like spectral unmixing can be skewed by narrowband residuals. These should be inoculated whenever 

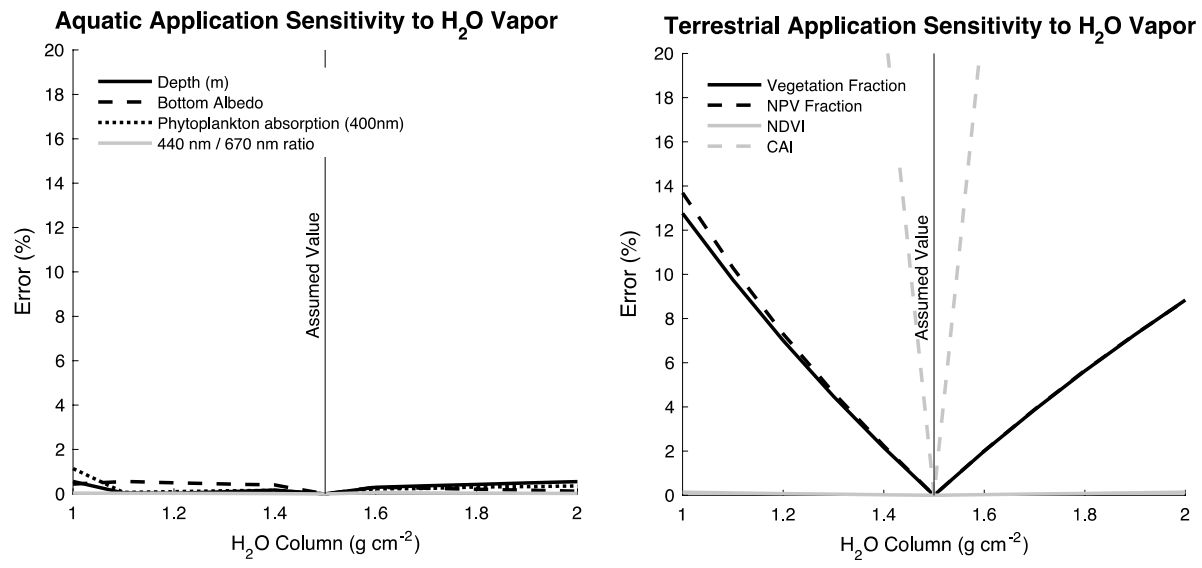

Fig. 9 Sensitivity of reference applications to misestimating atmospheric water vapor. Errors show the percent departure from the undistorted value of each estimated variable. Aquatic traits are the bottom albedo, phytoplankton absorption, and the band ratio of 440 and $670 \mathrm{~nm}$ that is often used as a proxy for chlorophyll-a. Terrestrial traits are the total fractional coverage of vegetation and Non-Photosynthetic Vegetation (NPV), the Normalized Difference Vegetation Index (NDVI), and the Cellulose Absorption Index (CAI)
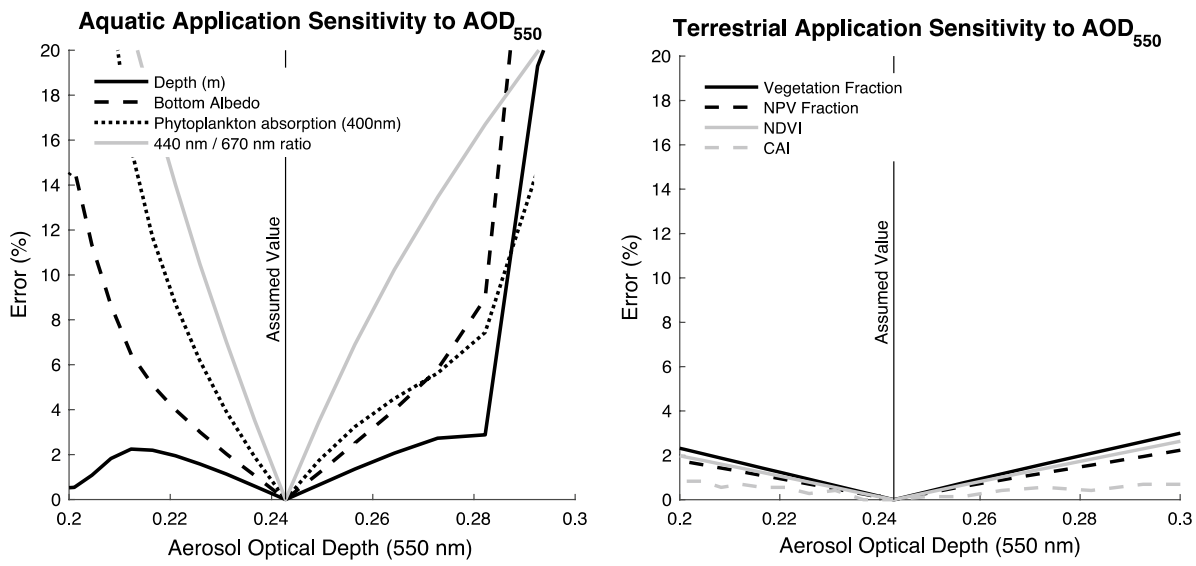

Fig. 10 Sensitivity of reference applications to misestimating aerosol optical depth. Errors show the percent departure from the undistorted value of each estimated variable

possible by incorporating the reflectance measurement error in an appropriate objective function. It is also widely understood that visible wavelength studies such as aquatic science are highly susceptible to aerosol interference. This also holds to a lesser degree for terrestrial vegetation due to the value of visible wavelengths for characterizing plant pigmentation and productivity. Due to the wide range of aerosol types and AODs that may appear in on global scales, estimating these parameters accurately will be important to achieve consistent results. 


\section{Atmospheric Studies}

While imaging spectrometers are primarily used to study the Earth's surface, certain atmospheric measurements have intrinsic scientific value. Solar-reflected imaging spectrometers typically operate at much higher spatial resolutions than purpose-built atmospheric sounding instruments, so they reveal unique fine-scale phenomena such as individual sources of greenhouse gas emissions or small cloud structures. Future orbital instruments will extend the reach of these investigations.

\subsection{Monitoring of Greenhouse Gas Sources and Urban Air Quality}

Most trace gases like $\mathrm{CH}_{4}$ and $\mathrm{CO}_{2}$ are predictable enough for accurate reflectance estimation. However, investigators can estimate these concentrations still more precisely to support specific campaign objectives. Recently, new investigators have pursued detection and mapping of point source greenhouse gas emitters (Frankenberg et al. 2016). Imaging spectrometers are suited for this purpose since they cannot only measure the total magnitude of an emissions plume, but also map its extent and-if spatial resolution is sufficient-trace it to specific source locations on the Earth's surface. In the case of $\mathrm{CH}_{4}$, such techniques could capture events such as spontaneous leaks as well as standard losses from fossil fuel transport and processing or biogenic emissions from animal husbandry. In many industries, a small fraction of facilities (the so-called superemitters) are responsible for a disproportionate fraction of total $\mathrm{CH}_{4}$ emissions. Cataloguing these superemitters offers an efficient path to reduce anthropogenic radiative forcing - and often reduces lost revenue for the extractive industry responsible. Thompson et al. (2016a) demonstrated detection of a large $\mathrm{CH}_{4}$ plume from orbit using the Hyperion imaging spectrometer, suggesting that future orbital missions may be capable of detecting the strongest $\mathrm{CH}_{4}$ superemitters.

Band ratios provide insufficient sensitivity to map local variability in greenhouse gases. Instead, investigations typically use the entire spectral measurement with techniques based on differential optical absorption spectroscopy, or DOAS (Thorpe et al. 2017). DOAS has also been used to monitor non-greenhouse trace gases such as $\mathrm{NO}_{2}$, which are important for urban air quality (Tack et al. 2017, Popp et al. 2012). A popular alternative is the matched filter (Thompson et al. 2015b). It uses the fact that for optically thin enhancements, the Beer-Lambert absorption reduces in first-order Taylor expansion to a linear function of optical path length. This allows fast, accurate retrievals of local enhancements relative to the background using a linear projection operator. To avoid confusion by other variability in the scene, it is common to first characterize the statistics of the local radiance background. This enables a whitening normalization to remove the effects of substrate and other incidental atmospheric variability. Figure 11 shows an example from the AVIRIS-NG instrument, acquired in October 2016. A $\mathrm{CO}_{2}$ plume from a powerplant is visible in the enhancement map at right.

\subsection{Cloud Properties}

Many existing orbital instruments can characterize cloud optical properties, such as thermodynamic phase, particle size, and optical depth, at kilometer scales. These properties relate to clouds' lifetimes, evolution, and radiative forcing potential. Imaging spectroscopy observations can provide complementary information on these properties at sub-kilometer spatial resolutions, revealing fine-scale variability that could help parameterize cloud 

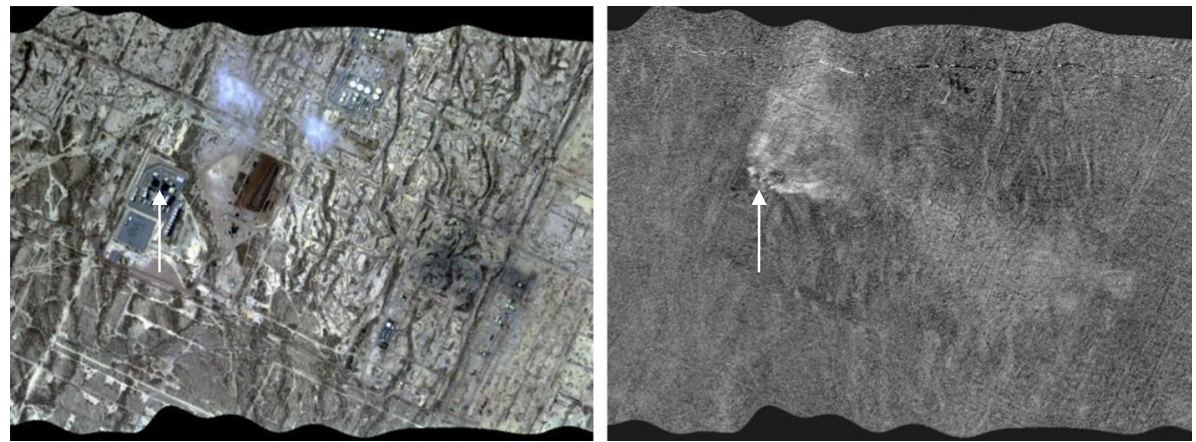

Fig. 11 AVIRIS-NG image from 29 October 2016. Left: visible RGB image. Right: enhancement of $\mathrm{CO}_{2}$ absorption via the Jacobian-based, columnwise matched filter approach of Thompson et al. (2015b). Arrows indicate a facility emitting a large $\mathrm{CO}_{2}$ plume

formation and evolution models for global climate models (Tan and Storelvmo 2016). The VSWIR interval reveals cloud-top particle size and optical depth, as well as thermodynamic phase (the partitioning of clouds into liquid and ice particles). A recent validation experiment demonstrated that joint spectrum fitting of the three water phases, described above in the context of atmospheric correction, could also retrieve cloud thermodynamic phase with high accuracy (Thompson et al. 2016b). Spectroscopic curve fitting can be less vulnerable to ambiguities in the retrieval than multi-band techniques using band ratiosparticularly for mixed cloud cases. The validation experiment observed the same cloud locations within $10 \mathrm{~min}$ from both an airborne imaging spectrometer and an in situ aircraft platform. The in situ platform ingested cloud particles through an external port; microscopic high-speed imaging of this airstream provided an authoritative direct classification.

Figure 12 shows an example of co-located spectra. The inset images show microscopic cloud particles: Rough shapes are ice, large annuli are supercooled water droplets, and small points are standard liquid cloud particles. The campaign demonstrated that the relative liquid and ice thicknesses retrieved from remote imaging spectroscopy at 1.4-1.8 $\mu \mathrm{m}$ were highly correlated with the clouds' actual liquid and ice content. Future orbital instruments could perform similar retrievals over wide spatiotemporal intervals - a new measurement modality to monitor cloud thermodynamic phase as climate changes (Thompson et al. 2018a).

\subsection{Cross-Track Uniformity and Spectral Response}

Sharp atmospheric features enable in-flight characterization of the instrument spectral response. This is useful to validate ground spectral calibration, to update calibrations over time, and to estimate response properties under realistic illumination and environmental conditions. One important artifact for some imaging spectrometers is the spectral "smile," also known as spectral non-uniformity or spectral aberration (Mouroulis et al. 2000). It is a consequence of optical aberrations causing the spectrometer entrance slit, representing the across-track swath, to be projected as a curve on the rectilinear detector array. This effect can be estimated in-flight from atmospheric absorption features (Gao et al. 2004, Guanter et al. 2006). These techniques are commonly used operationally, such as the study of Thompson et al. (2015b) which characterized the cross-track deviation in a linear shift through the wavelength change in the oxygen A band. The HATCH code was developed to correct imaging 


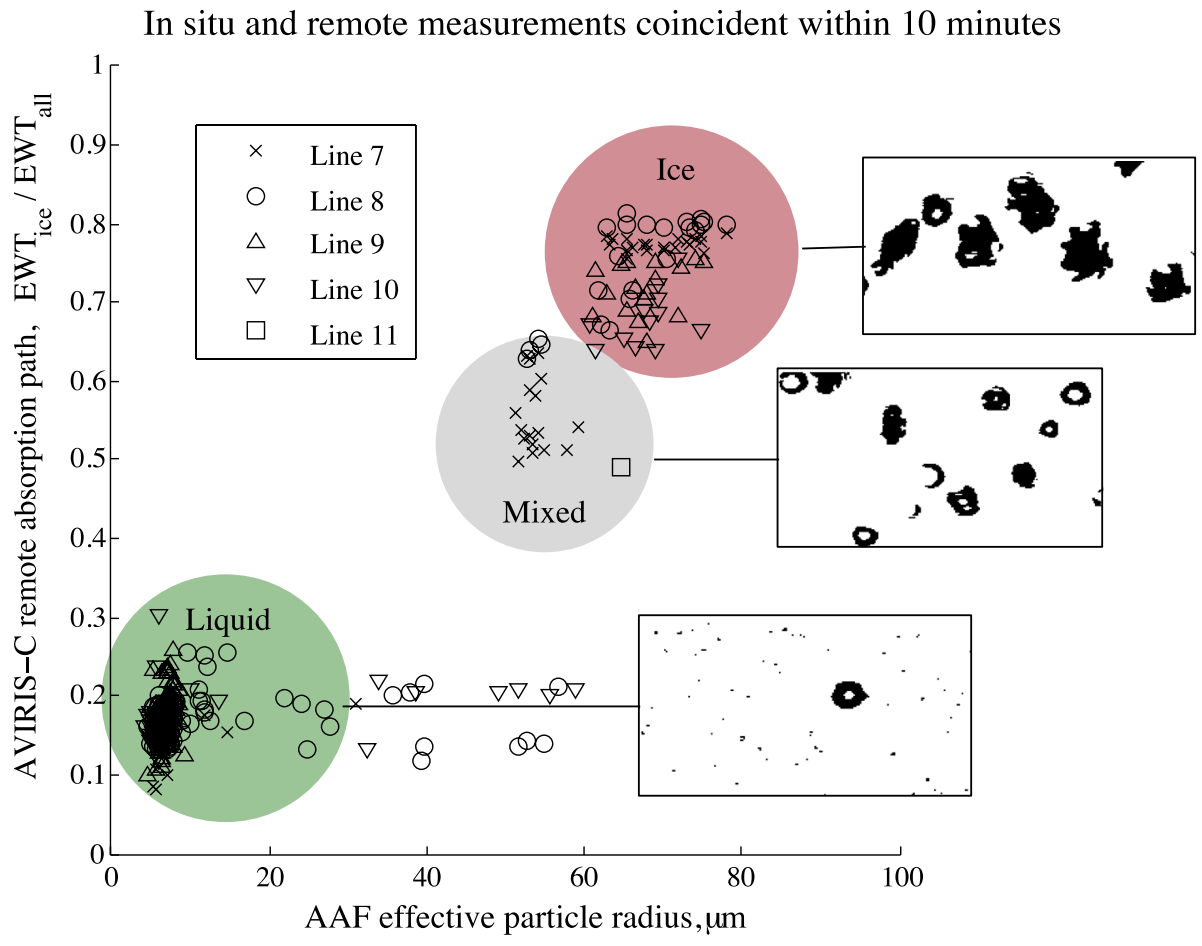

Fig. 12 Cloud particles measured at identical locations, less than $10 \mathrm{~min}$ apart by in situ high-speed imaging and remote imaging spectroscopy. The remotely estimated water fraction of ice $\left(\mathrm{EWT}_{\mathrm{ice}} / \mathrm{EWT}_{\text {all }}\right)$ indicates cloud particle phase. Each point in the plot is a spectrum from one of five flightlines ("lines 7-11"). Image inserts show direct microscopic images of cloud particles obtained in situ, confirming the remote classification; Atmospheric radiation measurement Aerial Facility (AAF). Adapted from Thompson et al. (2016b)

spectrometer data for the non-uniformity (Goetz et al. 2003). An optimized version of spectral non-uniformity compensation with respect to execution time and accuracy was published for operational processing (Richter et al. 2011), where the wavelength shift in across-track direction is modeled as a polynomial function; this feature is an integral part of the atmospheric correction. A similar approach is also implemented in the FLAASH code (Perkins et al. 2012). Atmospheric features can reveal other subtler aspects of the spectral response. Prior research has used sharp features like the oxygen A band to estimate the full width at half maximum (Kuhlmann et al. 2016). Recent studies have estimated more subtle tail deviations of the spectral response function from the ideal Gaussian line shape (Thompson et al. 2018b). Such features affect the response three to four orders of magnitude below the peak, but can still influence sensitive retrievals such as surface pressure estimates.

\section{Challenges and Future Directions}

In many respects, model-based atmospheric correction for VSWIR imaging spectrometers is a mature technology, with decades of regular operational use on airborne instruments. Under favorable conditions, investigations regularly achieve reflectance accuracy to within 
a $2-5 \%$ or better, as judged by many independent validation campaigns. However, the general atmospheric correction problem is far from solved. The best accuracies reported in prior validation studies belie significant planning, investigator field work and analyst attention to the atmospheric correction process. They may not represent the average-case result for a fully automated production system, which must handle global observations over many different atmospheres and challenging weather conditions. Global imaging spectroscopy will require sustained attention to atmospheric correction accuracy and algorithm development in order to meet the promise of improved access to data, reduce institutional "barriers to entry" for imaging spectroscopy products, and enable bias-free science investigations spanning many regions and climatologies. In addition, new and sensitive applications such as fine-scale ecosystem process mapping will require very high accuracy and consistency in atmospheric correction. Such applications rely on subtler spectral signatures, raising accuracy standards.

Several topics warrant additional attention for global spectroscopic studies. Arguably, trace gas estimation is now accurate enough that it is not a significant contributor to error in retrieved reflectance. In contrast, consistent aerosol estimation remains a challenge. Not only are the perturbations of aerosols spectrally smooth, and therefore more difficult to disentangle from surface reflectance effects, but they are also highly variable with respect to aerosol optical properties. Additionally, many current methods for aerosol estimation rely on shaded pixels that may not be apparent at orbital $30 \mathrm{~m}$ ground sampling distances. Applications like shallow water coastal studies and vegetation studies can be sensitive to slope changes in the aerosol-sensitive visible wavelengths. Fortunately, these applications also offer fairly strong constraints on reasonable surface reflectance shapes, enabling statistical recognition of aerosol contaminated data. This points toward the utility of future aerosol estimation methods that combine surface and atmosphere models, such as the Bayesian approach of Frouin and Pelletier (2015), or the optimal estimation approach used in atmospheric sounding instruments (Rodgers 2000). Optimal estimation was recently demonstrated with imaging spectrometer flight data, showing the feasibility of this approach (Thompson et al. 2018c). These unified inversions of surface and atmosphere hold several potential advantages: They could add statistical rigor, seamlessly incorporating domain knowledge or climatology in the form of statistical priors; they could combine surface and atmospheric information across the VSWIR interval, potentially resolving the problem of indeterminacy in smooth perturbations; and they could fit a joint solution encompassing multiple atmospheric correction steps that have conventionally been handled with independent sequential operations.

Another fruitful topic for further research is the characterization and propagation of uncertainties through the atmospheric correction process. Most current downstream algorithms rely on spectrum fitting and matching presuming uniform errors (and often, uncorrelated errors) across wavelengths. In practice, atmospheric correction uncertainties manifest more strongly in some channels than others and may induce spurious correlations. Reporting such errors would permit downstream algorithms to incorporate them to improve resilience against pathological atmospheric effects. Atmospheric correction should ideally respect the errors and correlations in the input data-the underlying instrument radiances.

Finally, there has been increasing recognition in the potential for VSWIR atmospheric science investigations by imaging spectrometers. The ability to image atmospheric content at sub-kilometer spatial resolutions opens new applications including monitoring anthropogenic greenhouse gases, cloud studies, and process studies of ecosystem gas exchange and evapotranspiration. Despite the long history of success to date in atmospheric correction, 
VSWIR atmospheric studies remain an exciting, relevant, and challenging domain for ongoing study.

Acknowledgements We acknowledge the critical support and facilitation of the International Space Science Institute (ISSI), Bern, Switzerland. A portion of this research was performed at the Jet Propulsion Laboratory, California Institute of Technology. AVIRIS-C and AVIRIS-NG are supported by National Aeronautics and Space Administration Earth Science, Science Mission Directorate. U.S. Federal Government support acknowledged. Copyright 2018. All Rights Reserved.

\section{References}

ASTER (2018) The advanced spaceborne thermal emission and reflection radiometer global digital elevation map. https://asterweb.jpl.nasa.gov/gdem.asp. Last access 17 May 2018

Bachmann M, Makarau A, Segl K, Richter R (2015) Estimating the influence of spectral and radiometric calibration uncertainties on EnMAP data products-examples for ground reflectance retrieval and vegetation indices. Remote Sens 7(8):10689-10714

Berk A et al (2016a) Algorithm theoretic basis document (ATBD) for next generation MODTRAN ${ }^{\circledR}$. Spectral Sciences Inc, Burlington

Berk A, van den Bosch J, Hawes F, Perkins T, Conforti PF, Anderson GP, Kennett RG, Acharya PK (2016b). MODTRAN $^{\circledR} 6.0 .0$ user's manual (revision 5). Spectral Sciences, Inc., Burlington. SSI-TR-685

Bernstein LS, Adler-Golden SM, Sundberg RL, Levine RY, Perkins TC, Berk A, Ratkowski AJ, Felde G, Hoke ML (2005) Validation of the QUick Atmospheric Correction (QUAC) algorithm for VNIRSWIR multi-and hyperspectral imagery. In: Defense and security. International Society for Optics and Photonics, pp 668-678

Boardman JW (1998) Post-ATREM polishing of AVIRIS apparent reflectance data using EFFORT: a lesson in accuracy versus precision. In: Summaries of the 7th JPL airborne earth science workshop, JPL Publication 97-21, 1:53

Bruegge CJ, Conel JE, Margolis JS, Green RO, Toon GC, Carrere V, Holm RG, Hoover G (1990) In-situ atmospheric water-vapor retrieval in support of AVIRIS validation. In: Proceedings of SPIE - The International Society for Optical Engineering, vol 1298

Cannizzaro JP, Carder KL (2006) Estimating chlorophyll a concentrations from remote-sensing reflectance in optically shallow waters. Remote Sens Environ 101(2006):13-24

Carlson TN, Ripley DA (1997) On the relation between NDVI, fractional vegetation cover, and leaf area index. Remote Sens Environ 62(3):241-252

Clark RN, Swayze GA, Livo KE, Kokaly RF, Sutley SJ, Dalton JB, McDougal RR, Gent CA (2003) Imaging spectroscopy: earth and planetary remote sensing with the USGS Tetracorder and expert systems. J Geophys Res 108:5131. https://doi.org/10.1029/2002JE001847,E12

Conel JE, Green RO, Vane G, Bruegge CJ, Alley RE (1987) AIS-2 radiometry and a comparison of methods for the recovery of ground reflectance. In: Vane G (ed) Proceedings of the 3rd airborne imaging spectrometer data analysis workshop, JPL Publ. volume 87-30 Jet Propulsion Laboratory, Pasadena, CA, pp $18-47$

Frankenberg C, Thorpe A, Thompson DR, Hulley G, Kort E, Vance N, Borchard J, Krings T, Gerilowski K, Sweeney C, Conley S, Bue B, Aubrey A, Hook S, Green RO (2016) Airborne methane remote measurements reveal heavy-tail flux distribution in Four Corners region. Proc Natl Acade Sci 113(35):9734-9739

Fraser RS, Kaufman YJ (1985) The relative importance of aerosol scattering and absorption in remote sensing. IEEE J Geosci Remote Sens GE-23:525-633

Frouin Robert, Pelletier Bruno (2015) Bayesian methodology for inverting satellite ocean-color data. Remote Sens Environ 159:332-360

Fu Q, Liou KN (1992) On the correlated k-distribution method for radiative transfer in nonhomogeneous atmospheres. J Atmos Sci 49(22):2139-2156

Gao B-C, Goetz AF (1990) Column atmospheric water vapor and vegetation liquid water retrievals from airborne imaging spectrometer data. J Geophys Res Atmos 95(D4):3549-3564

Gao B-C, Goetzt AF (1995) Retrieval of equivalent water thickness and information related to biochemical components of vegetation canopies from AVIRIS data. Remote Sens Environ 52(3):155-162 
Gao B-C, Kaufman YJ (1995) Selection of the 1.375- $\mu$ m MODIS channel for remote sensing of cirrus clouds and stratospheric aerosols from space. J Atmos Sci 52:4231-4237

Gao B-C, Liu M (2013) A fast smoothing algorithm for post-processing of surface reflectance spectra retrieved from airborne imaging spectrometer data. Sensors 13:13879-13891. https://doi. org/10.3390/s131013879

Gao B-C, Heidebrecht KB, Goetz AFH (1993) Derivation of scaled surface reflectances from AVIRIS data. Remote Sens Environ 44:165-178

Gao B-C et al (1998) Correction of thin cirrus path radiance in the 0.4-1.0 $\mu \mathrm{m}$ spectral region using the sensitive 1.375- $\mu \mathrm{m}$ cirrus detecting channel. J Geophys Res 103:32169-32176

Gao B-C, Montes MJ, Ahmad Z, Davis CO (2000) Atmospheric correction algorithm for hyperspectral remote sensing of ocean color from space. Appl Opt 39(6):887-896

Gao B-C, Yang P, Han W, Li R-R, Wiscombe WJ (2002) An algorithm using visible and 1.38-micron channels to retrieve cirrus cloud reflectances from aircraft and satellite data. IEEE Trans. Geosci. Remote Sensing 40:1659-1668

Gao B-C, Montes MJ, Davis CO (2004) Refinement of wavelength calibrations of hyperspectral imaging data using a spectrum-matching technique. Remote Sens Environ 90:424-433

Gao B-C, Montes MJ, Davis CO, Goetz AF (2009) Atmospheric correction algorithms for hyperspectral remote sensing data of land and ocean. Remote Sens Environ 113:S17-S24

Goetz AFH, Kindel BC, Ferri M, Qu Z (2003) HATCH: results from simulated radiances, AVIRIS and Hyperion. IEEE TGRS 41:1215-1222

Green RO, Carrere V, Conel JE (1989) Measurement of atmospheric water vapor using the Airborne Visible/Infrared Imaging Spectrometer. In: Proceedings of the ASPRS conference on image processing, Reno, NV

Green RO, Conel JE, Roberts DA (1993) Estimation of aerosol optical depth, pressure elevation, water vapor, and calculation of apparent surface reflectance from radiance measured by the airborne visible/infrared imaging spectrometer (AVIRIS) using a radiative transfer code. Optical Engineering and Photonics in Aerospace Sensing. International Society for Optics and Photonics. pp 2-11

Green RO, Painter TH, Roberts DA, Dozier J (2006) Measuring the expressed abundance of the three phases of water with an imaging spectrometer over melting snow. Water Resour Res 42(10):W10402

Guanter L, Richter R, Moreno J (2006) Spectral calibration of hyperspectral imagery using atmospheric absorption features. Appl Opt 45:2360-2370

Guanter L, Estellés V, Moreno J (2007) Spectral calibration and atmospheric correction of ultra-fine spectral and spatial resolution remote sensing data. Application to CASI-1500 data. Remote Sens Environ 109(1):54-65

Guanter L, Gómez-Chova L, Moreno J (2008) Coupled retrieval of aerosol optical thickness, columnar water vapor and surface reflectance maps from ENVISAT/MERIS data over land. Remote Sens Environ 112(6):2898-2913

Hagolle O, Huc M, Villa Pascual D, Dedieu G (2015) A multi-temporal and multi-spectral method to estimate aerosol optical thickness over land, for the atmospheric correction of FormoSat-2, LandSat, VEN $\mu$ S and Sentinel-2 images. Remote Sens 7(3):2668-2691

Herold M, Roberts DA, Gardner ME, Dennison PE (2004) Spectrometry for urban area remote sensing-development and analysis of a spectral library from 350 to $2400 \mathrm{~nm}$. Remote Sens Environ 91(3):304-319

Hu B, Lucht W, Strahler AH (1999) The interrrelationship of atmospheric correction of reflectances and surface BRDF retrieval: a sensitivity study. IEEE Trans Geosci Remote Sens 37:724-738

Jensen DJ, Simard M, Cavanaugh KC, Thompson DR (2018) Imaging spectroscopy BRDF correction for mapping Louisiana's coastal ecosystems. IEEE Trans Geosci Remote Sens 56(3):1739-1748

Kaufman YJ, Sendra C (1988) Algorithm for automatic atmospheric corrections to visible and near-IR satellite imagery. Int J Remote Sens 9(8):1357-1381

Kaufman YJ, Wald A, Remer LA, Gao B-C, Li RR, Flynn L (1997) The MODIS 2.1- $\mu$ m channel—correlation with visible reflectance for use in remote sensing of aerosol. IEEE Trans Geosci Remote Sens 35:1286-1298

Kobayashi S, Sanga-Ngoie K (2008) The integrated radiometric correction of optical remote sensing imageries. Int J Remote Sens 29:5957-5985

Kokaly RF, Asner GP, Ollinger SV, Martin ME, Wessman CA (2009) Characterizing canopy biochemistry from imaging spectroscopy and its application to ecosystem studies. Remote Sens Environ 113:S78-S91

Kruse FA (1988) Use of airborne imaging spectrometer data to map minerals associated with hydrothermally altered rocks in the northern Grapevine Mountains, Nevada and California. Remote Sens Environ 24:31-51 
Kruse FA (2004) Comparison of ATREM, ACORN, and FLAASH atmospheric corrections using lowaltitude AVIRIS data of Boulder, CO. In: Summaries of 13th JPL Airborne Geoscience Workshop, Jet Propulsion Laboratory, Pasadena, CA

Kuhlmann G, Hueni A, Damm A, Brunner D (2016) An algorithm for in-flight spectral calibration of imaging spectrometers. Remote Sens 8:1017

Lee Z, Carder KL, Mobley CD, Steward RG, Patch JS (1998) Hyperspectral remote sensing for shallow waters. I. A semianalytical model. Appl Opt 37(27):6329-6338

Lee Z, Carder KL, Mobley CD, Steward RG, Patch JS (1999) Hyperspectral remote sensing for shallow waters: 2. Deriving bottom depths and water properties by optimization. Appl Opt 38(18):3831-3843

Li A, Wang Q, Bian J, Lei G (2015) An improved physics-based model for topographic correction of Landsat TM images. Remote Sens 7:6296-6319

Loyola DG, Coldewey-Egbers RM, Dameris M, Gamy H, Stenke A, Van Roozendael M, Lerot C, Balis D, Koukouli M (2009) Global long-term-monitoring of the ozone layer-a prerequisite for predictions. Int J Remote Sens 30:4295-4318

Makarau A, Richter R, Müller R, Reinartz P (2014) Haze detection and removal in remotely sensed multispectral imagery. IEEE TGRS 52:5895-5905

Makarau A, Richter R, Schläpfer D, Reinartz P (2016) Combined haze and cirrus removal for mulispectral imagery. IEEE GRSL 13:379-383

Makarau A, Richter R, Schläpfer D, Reinartz P (2017) APDA water vapor retrieval validation for Sentinel-2 imagery. IEEE GRSL 14:227-231

Matthew MW, Adler-Golden SM, Berk A, Felde G, Anderson GP, Gorodetzky D, Paswaters S, Shippert M (2002) Atmospheric correction of spectral imagery: evaluation of the FLAASH algorithm with AVIRIS data. In: Proceedings of the 31st applied imagery pattern recognition workshop. IEEE, pp $157-163$

Mouroulis P, Green RO, Chrien TG (2000) Design of pushbroom imaging spectrometers for optimum recovery of spectroscopic and spatial information. Appl Opt 39:2210-2220

Mumby PJ, Skirving W, Strong AE, Hardy JT, LeDrew EF, Hochberg EJ et al (2004) Remote sensing of coral reefs and their physical environment. Mar Pollut Bull 48(3):219-228

Nagler PL, Inoue Y, Glenn EP, Russ AL, Daughtry CST (2003) Cellulose absorption index (CAI) to quantify mixed soil-plant litter scenes. Remote Sens Environ 87(2):310-325

Palacios SL, Kudela RM, Guild LS, Negrey KH, Torres-Perez J, Broughton J (2015) Remote sensing of phytoplankton functional types in the coastal ocean from the HyspIRI Preparatory Flight Campaign. Remote Sens Environ 167:269-280

Perkins T, Adler-Golden S, Matthew MW, Berk A, Bernstein LS, Lee J, Fox M (2012) Speed and accuracy improvements in FLAASH atmospheric correction of hyperspectral imagery. Opt Eng 51:111707-111708

Popp C, Brunner D, Damm A, Van Roozendael M, Fayt C, Buchmann B (2012) High-resolution NO2 remote sensing from the Airborne Prism EXperiment (APEX) imaging spectrometer. Atmos Meas Tech 5(9):2211-2225

Reinersman PN, Carder KL, Chen RF (1998) Satellite-sensor calibration verification with the cloud-shadow method. Appl Opt 37:5541-5549

Riano D, Chuvieco E, Salas J, Aguado I (2003) Assessment of different topographic corrections in LandsatTM data for mapping vegetation types. IEEE TGRS 41:1056-1061

Richter R (1998) Correction of satellite imagery over mountainous terrain. Appl Opt 37:4004-4015

Richter R, Schlaepfer D (2002) Geo-atmospheric processing of airborne imaging spectrometry data, Part 2: atmospheric/topographic correction. Int J Remote Sens 23(13):2631-2649

Richter R, Kellenberger T, Kaufmann H (2009) Comparison of topographic correction methods. Remote Sens 1:184-196

Richter R, Schläpfer D, Müller A (2011) Operational atmospheric correction for imaging spectrometers accounting for the smile effect. IEEE TGRS 49:1772-1780

Richter R, Heege T, Kiselev V, Schläpfer D (2014) Correction of ozone influence on TOA radiance. Int J Remote Sens 35:8044-8056

Roberts DA, Yamaguchi Y, Lyon R (1986) Comparison of various techniques for calibration of AIS data. In: Vane G, Goetz AFH (eds) Proceedings of the 2nd airborne imaging spectrometer data analysis workshop, JPL Publication 86-35, 21-30, Jet Propulsion Lab, Pasadena, CA

Roberts DA, Yamaguchi Y, Lyon R (1986) Comparison of various techniques for calibration of AIS data. In: Vane G, Goetz AFH (eds) Proceedings of the 2nd Airborne imaging spectrometer data analysis workshop, JPL Publication, vol 86-35, Jet Propulsion Lab, Pasadena, CA, pp 21-30

Rodgers CD (2000) Inverse methods for atmospheric sounding: theory and practice. World Scientific, Singapore 
Sandmeier S, Itten KI (1997) A physically-based model to correct atmospheric and illumination effects in optical satellite data of rugged terrain. IEEE TGRS 35:708-717

Schaepman-Strub G, Schaepman ME, Painter TH, Dangel S, Martonchik JV (2006) Reflectance quantities in optical remote sensing-definitions and case studies. Remote Sens Environ 103(1):27-42

Schläpfer D, Richter R (2011) Spectral polishing of high resolution imaging spectroscopy data. In: Proceedings of the 7th SIG-IS workshop on imaging spectroscopy, Edinburgh, UK, p 7. http://www.danie 1-schlaepfer.ch/pdf/Schlaepfer_IS2011_polish.pdf

Schläpfer D, Borel CC, Keller J, Itten KI (1998) Atmospheric precorrected differential absorption technique to retrieve columnar water vapor. Remote Sens Environ 65(3):353-366

Schläpfer D, Richter R, Damm A (2013) Correction of shadowing in imaging spectroscopy data by quantification of the proportion of diffuse illumination. In: Presented at the 8th EARSeL SIG-IS Workshop on Imaging Spectroscopy, Nantes, FR, pp 10. http://www.daniel-schlaepfer.ch/pdf/Schlaepfer_Earsel2013 _Shadow.pdf

Schläpfer D, Richter R, Feingersh T (2015) Operational BRDF effects correction for wide-field-of-view optical scanners (BREFCOR). IEEE Trans Geosci Remote Sens 53(4):1855-1864

Shepherd JD, Dymond JR (2003) Correcting satellite imagery for the variance of reflectance and illumination with topography. Int J Remote Sens 24:3503-3514

Soenen SA, Peddle DR, Coburn CA (2005) SCS + C: a modified sun-canopy-sensor topographic correction in forested terrain2. IEEE TGRS 43:2148-2159

SRTM (2018) Shuttle radar topography mission digital elevation model. https://lta.cr.usgs.gov/SRTM1Arc. Last access 17 May 2018

Stamnes K, Tsay SC, Wiscombe W, Jayaweera K (1988) Numerically stable algorithm for discreteordinate-method radiative transfer in multiple scattering and emitting layered media. Appl Opt 27(12):2502-2509

Tack F, Merlaud A, Iordache M-D, Danckaert T, Yu H, Fayt C, Meuleman K, Deutsch F, Fierens F, Van Roozendael M (2017) High-resolution mapping of the $\mathrm{NO}_{2}$ spatial distribution over Belgian urban areas based on airborne APEX remote sensing. Atmos Meas Tech 10:1665-1688

Tan I, Storelvmo T (2016) Sensitivity study on the influence of cloud microphysical parameters on mixedphase cloud thermodynamic phase partitioning in CAM5. J Atmos Sci 73(2):709-728

Tanré D, Herman M, Deschamps PY (1981) Influence of the background contribution upon space measurements of ground reflectances. Appl Opt 20:3676-3684

Tanré D, Herman M, Deschamps PY (1983) Influence of the atmosphere on space measurements of directional properties. Appl Opt 22(5):733-741

Teillet PM, Guindon B, Goodenough DG (1982) On the slope-aspect correction of multispectral scanner data. Can J Remote Sens 8:84-106

Thompson DR, Gao BC, Green RO, Roberts DA, Dennison PE, Lundeen SR (2015a) Atmospheric correction for global mapping spectroscopy: ATREM advances for the HyspIRI preparatory campaign. Remote Sens Environ 167:64-77

Thompson DR, Leifer I, Bovensmann H, Eastwood M, Fladeland M, Frankenberg C, Gerilowski K, Green RO, Kratwurst S, Krings T, Luna B, Thorpe A (2015b) Real-time remote detection and measurement for airborne imaging spectroscopy: a case study with methane. Atmos Meas Tech 8:4383-4397

Thompson DR, Siedel F, Gao B-C, Gierach M, Kudela R, Green RO, Mouroulis P (2015c) Optimizing solar irradiance for coastal spectroscopy. Geophys Res Lett 42:4116-4123

Thompson DR, Thorpe AK, Frankenberg C, Green RO, Duren R, Hollstein A, Guanter L, Middleton E, Ong L, Ungar S (2016a) Orbital measurement of the Aliso Canyon $\mathrm{CH}_{4}$ super-emitter. Geophys Res Lett 43:6571-6578

Thompson DR, McCubbin I, Gao B-C, Green RO, Matthews AA, Mei F, Meyer K, Platnick S, Schmid B, Tomlinson J, Wilcox E (2016b) Measuring cloud thermodynamic phase with shortwave infrared imaging spectroscopy. J Geophys Res Atmos 121(15):9174-9190

Thompson DR, Boardman JW, Eastwood ML, Green RO, Haag JM, Mouroulis P, Van Gorp BE (2018a) Imaging spectrometer stray spectral response: in-flight characterization, correction, and validation. Remote Sens Environ 204:850-860

Thompson DR, Kahn BH, Green RO, Chien SA, Middleton EM, Tran DQ (2018b) Global spectroscopic survey of cloud thermodynamic phase at high spatial resolution, 2005-2015. Atmos Meas Tech 11:1019-1030. https://doi.org/10.5194/amt-11-1019-2018

Thompson DR, Natraj V, Green RO, Helmlinger MC, Gao B-C, Eastwood ML (2018c) Optimal estimation for imaging spectrometer atmospheric correction. Remote Sens Environ. https://doi.org/10.1016/j. rse.2018.07.003

Thorpe AK, Frankenberg C, Thompson DR, Duren RM, Aubrey AD, Bue BD, Green RO, Gerilowski K, Krings T, Borchardt J, Kort EA, Sweeney C, Conley S, Roberts DA, Dennison PE (2017) Airborne 
DOAS retrievals of methane, carbon dioxide, and water vapor concentrations at high spatial resolution: application to AVIRIS-NG. Atmos Meas Tech 10(10):3833-3850

United States National Bureau of Standards, Nicodemus FE (1977) Geometrical considerations and nomenclature for reflectance, vol 160. US Department of Commerce, National Bureau of Standards

Ustin SL, Roberts DA, Gamon JA, Asner GP, Green RO (2004) Using imaging spectroscopy to study ecosystem processes and properties. Bioscience 54(6):523-534

Vermote EF, El-Saleous N, Justice CO, Kaufman YJ, Privette JL, Remer L, Roger JC, Tanré D (1997a) Atmospheric correction of visible to middle infrared EOS-MODIS data over land surface: background, operational algorithm and validation. J Geophys Res 102:17131-17141

Vermote EF, Tanré D, Deuzé JL, Herman M, Morcrette JJ (1997b) Second simulation of the satellite signal in the solar spectrum, 6S: an overview. IEEE Trans Geosci Remote Sens 35:675-686

Weyermann J, Damm A, Kneubuhler M, Schaepman ME (2014) Correction of reflectance anisotropy effects of vegetation on airborne spectroscopy data and derived products. IEEE Trans Geosci Remote Sens 52(1):616-627

Yamamoto H, Tsuchida S, Yoshioka H (2008) A study on ASTER/MODIS radiometric and atmospheric correction. IGARSS. https://doi.org/10.1109/IGARS.2008.4779982

Zhang Y, Guindon B, Cihlar J (2002) An image transform to characterize and compensate for spatial variations in thin cloud contamination of Landsat images. Remote Sens Environ 82(2-3):173-187 